\title{
TMBIM6, a potential virus target protein identified by integrated multiomics data analysis in SARS-CoV-2-infected host cells
}

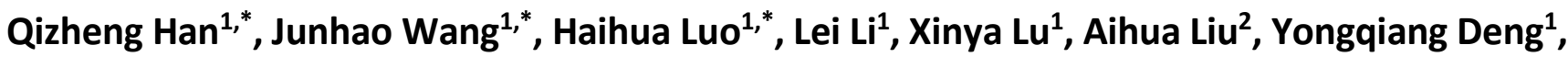 \\ Yong Jiang ${ }^{1}$
}

${ }^{1}$ Guangdong Provincial Key Laboratory of Proteomics, State Key Laboratory of Organ Failure Research, School of Basic Medical Sciences, Southern Medical University, Guangzhou, China

${ }^{2}$ Department of Respiratory and Critical Care Medicine, Nanfang Hospital, Southern Medical University, Guangzhou, China

${ }^{*}$ Equal contribution

Correspondence to: Yong Jiang, Yongqiang Deng, Aihua Liu; email: jiang48231@163.com, https://orcid.org/0000-0002-80875717; dengyongq08@i.smu.edu.cn; lah47158@163.com, https://orcid.org/0000-0003-3273-6664

Keywords: SARS-CoV-2, COVID-19, TMBIM6, apoptosis, multiomics data, bioinformatics

Received: September 18, $2020 \quad$ Accepted: February 16, $2021 \quad$ Published: March 19, 2021

Copyright: ( 2021 Han et al. This is an open access article distributed under the terms of the Creative Commons Attribution License (CC BY 3.0), which permits unrestricted use, distribution, and reproduction in any medium, provided the original author and source are credited.

\begin{abstract}
Coronavirus disease 2019 (COVID-19) is caused by severe acute respiratory syndrome coronavirus 2 (SARS-CoV2). In this study, we collected open access data to analyze the mechanisms associated with SARS-CoV-2 infection. Gene set enrichment analysis (GSEA) revealed that apoptosis-related pathways were enriched in the cells after SARS-CoV-2 infection, and the results of differential expression analysis showed that biological functions related to endoplasmic reticulum stress (ERS) and lipid metabolism were disordered. TMBIM6 was identified as a potential target for SARS-CoV-2 in host cells through weighted gene coexpression network analysis (WGCNA) of the time course of expression of host and viral proteins. The expression and related functions of TMBIM6 were subsequently analyzed to illuminate how viral proteins interfere with the physiological function of host cells. The potential function of viral proteins was further analyzed by GEne Network Inference with Ensemble of trees (GENIE3). This study identified TMBIM6 as a target protein associated with the pathogenesis of SARS-CoV-2, which might provide a novel therapeutic approach for COVID19 in the future.
\end{abstract}

\section{INTRODUCTION}

The outbreak of SARS-CoV-2 has disseminated to 216 countries and regions around the world [1]. The pneumonia patients infected by this novel coronavirus have clinical manifestations that include fever, fatigue and dry cough; approximately half of them develop dyspnea one week later, and some patients with severe disease progress rapidly to acute respiratory distress syndrome (ARDS), septic shock and metabolic acidosis $[2,3]$. The 29,903-nucleotide genome of SARS-CoV-2 encodes 14 major open reading frames (ORFs), which can be further processed into 4 structural proteins, namely, the glycoprotein spike (S), envelope (E), nucleocapsid $(\mathrm{N})$ and membrane $(\mathrm{M}), 16$ nonstructural proteins (nsp1 to nsp16), and at least 8 accessory proteins (ORF3a, ORF6, ORF7a, ORF7b, ORF8, ORF9a, ORF9b and ORF10) $[4,5]$. Similar to SARS$\mathrm{CoV}[6,7]$, the spike protein of SARS-CoV-2 directly interacts with the receptor ACE2 on the membrane of human airway epithelial cells to promote virus invasion $[8,9]$. To date, many studies have focused on the receptors for the spike protein of SARS-CoV-2, especially ACE2; however, the intracellular mechanism used by the virus to achieve amplification and regulate the protein expression of host cells is largely unknown. 
Due to the rapid development of omic techniques, it is possible to systematically illuminate the mechanism underlying the cellular response to the virus. Recently, Bojkova et al. investigated protein expression in host cells infected with SARS-CoV-2 by translatome and proteome data analysis [10]; Emanuel et al. investigated the expression of genes in cells infected with SARS-CoV-2 by RNA sequencing (RNA seq) [11]. Previous studies have demonstrated that increased synthesis of viral proteins is a prerequisite for virus amplification in host cells, and the virus might disrupt or hijack the intracellular anti-virus mechanism to support viral propagation. Further efforts are needed to illustrate the molecular drivers of SARS-CoV-2 pathogenesis.

In this study, gene set enrichment analysis (GSEA) with proteome data was performed to analyze the enriched signaling pathways of differentially expressed proteins induced by SARS-CoV-2 virus invasion. Differential expression analysis was utilized to obtain host proteins regulated by SARS-CoV-2 at the posttranscriptional level. After weighted coexpression network analysis (WGCNA) of the proteome data, we identified a key protein, TMBIM6, that was highly coexpressed with the viral proteins. Moreover, the regulatory proteins associated with the viral proteins were predicted by GEne Network Inference with Ensemble of trees (GENIE3). In general, through integrated bioinformatic analysis of transcriptome, translatome and proteome data, we found that the TMBIM6 protein in host cells was inhibited by SARSCoV-2 at the posttranscriptional level to mediate the host cell response to virus infection.

\section{RESULTS}

\section{Open access data from human tissues and cells infected with SARS-CoV-2 virus}

Proteome and translatome data from human Caco-2 cells infected with SARS-CoV-2 from Bojkova et al. were downloaded and used for subsequent analysis [10]. This data consisted of the quantification of 6,381 proteins in human Caco- 2 cell secretomes at four time points after infection with SARS-CoV-2 virus. We also obtained transcriptome data of Caco-2 cells infected with SARS-CoV-2 at different time points from Emanuel et al., which consists of 45058 genes with quantifications in Caco-2 cells [11]. The transcriptome data of autopsied lungs from patients who died due to SARS-CoV-2 infection (GSE150316) and different virus-infected A549 cells [12] were used for subsequent verification. The proteome data from cells infected with SARS-CoV-2 [13], influenza A virus (IAV) [14] and respiratory syncytial virus (RSV) [15], which provided the information of differentially expressed proteins, were also collected as a source of circumstantial evidence.

\section{Host cellular response to SARS-CoV-2}

With the proteome data, we first compared the protein expression in SARS-CoV-2-infected cells and mockinfected cells at different times. Through GSEA, we obtained the enrichment results of four time points separately on the proteome data with $P$ value $<0.05$. The results are then merged into one heatmap [16]. Because the influence of the early virus is little significant, we paid more attention to the influence of the virus at 24 hours. At the same time, in order to better display the results, we sorted the enrichment results at 24 hours according to the $P$ value, and the enrichment results at other time points were displayed in the order of 24 hours. If there is no enrichment for a certain pathway at a certain time, we will display it with a grey module (Figure 1A). Consistent with the findings of Appelberg et al. [17], our results demonstrated that the ErbB, PI3K-AKT, HIF-1 and Rap1 signaling pathways were activated in Caco-2 cells infected with SARS-CoV-2. Interestingly, we also found that some metabolism-related signaling pathways, including protein processing in the endoplasmic reticulum (ER), carbon metabolism, ribosome biogenesis in eukaryotes, calcium signaling pathway and glycolysis/ gluconeogenesis, were involved in the host cellular response to SARS-CoV-2 invasion.

\section{Identification of host proteins influenced by SARS- CoV-2}

With transcriptome data, the $\mathrm{R}$ package of Limmavoom was used to analyze differentially expressed genes (DEGs), which were visualized by a volcano plot (Figure 1B), and differentially expressed proteins (DEPs) were defined by two-sided unpaired student's $t$ test with equal variance assumed according to the original author using translatome data. To understand SARS-CoV-2's influence on cells at the posttranscriptional level, and remove some of the stress responses made by host cells at the transcriptional level due to SARS-CoV-2's invasion, we performed intersection analysis to identify the overlap of proteins encoded by non-differentially expressed genes (NDEGs) and DEPs in Caco-2 cells infected with SARS-CoV-2 (Figure 1C). Interestingly, we found that most differentially expressed proteins are translated by non-differentially expressed genes. Further analysis of Gene Ontology (GO) enrichment showed that the 192 shared proteins might involve in several biological process, including mitochondria-related functions, cholesterol biosynthesis processes and protein transport 
A

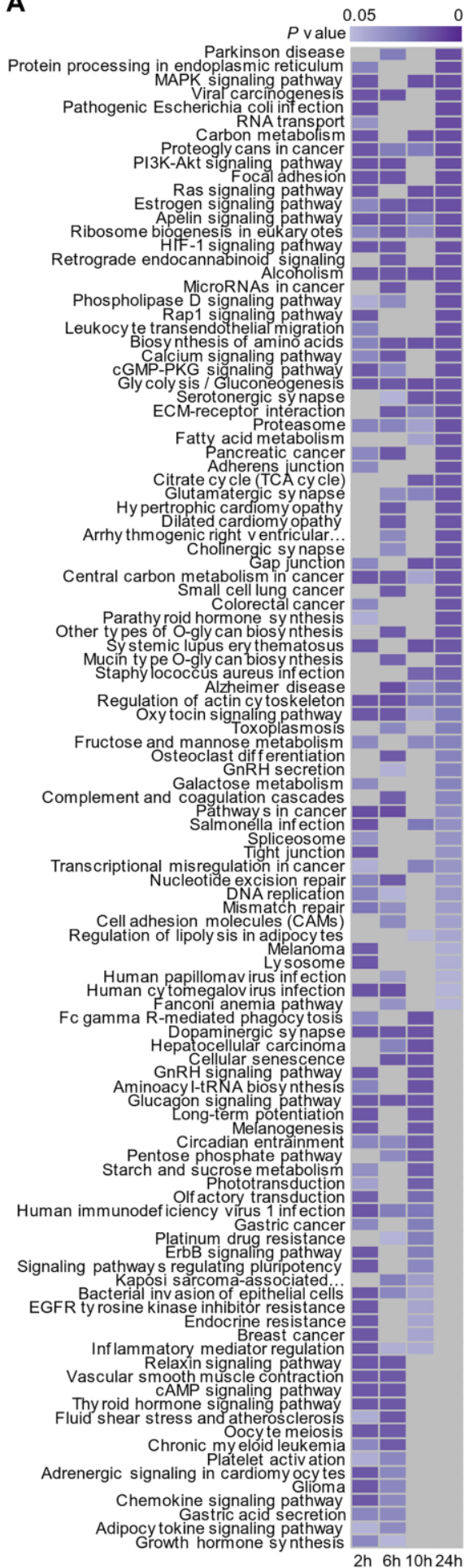

B

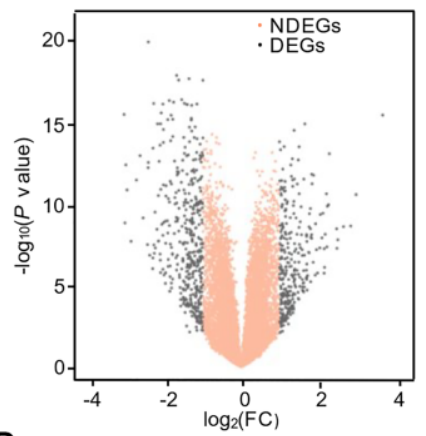

D

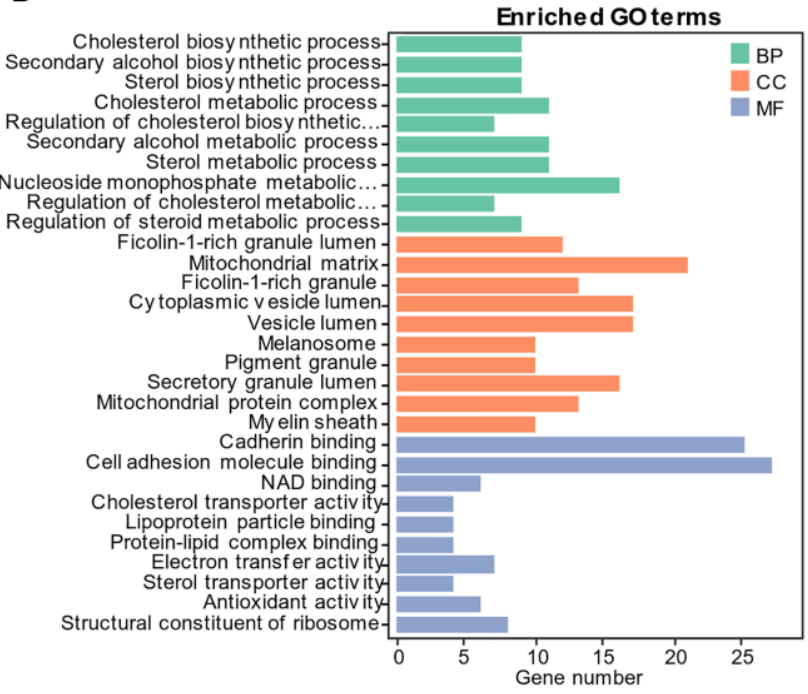

E

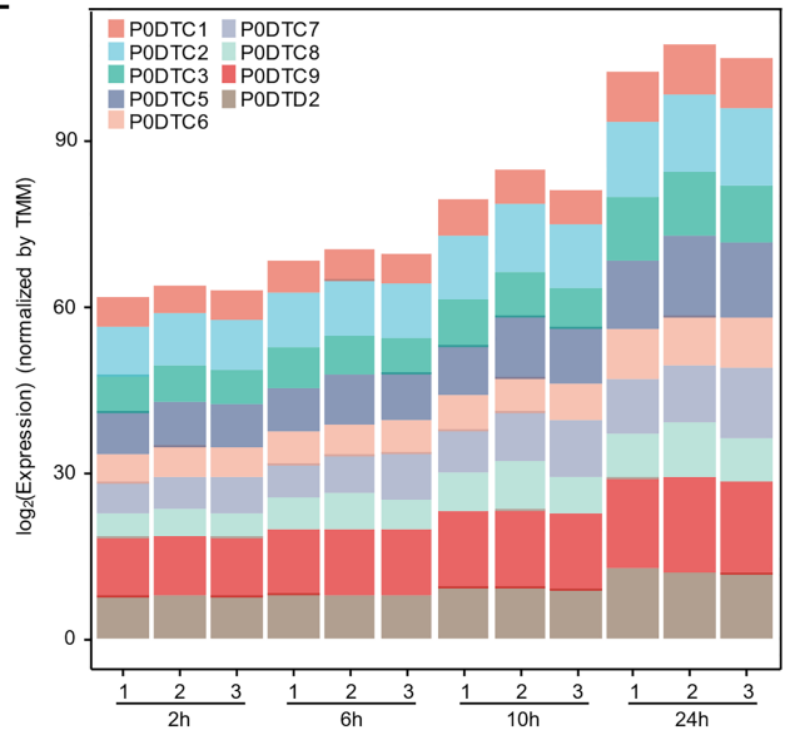

Figure. 1. Time-resolved multiomics profiling of the cellular response to SARS-COV-2 infection. (A) Gene set enrichment analysis by time series. Significant KEGG terms $(P$ value $<0.05, n=3)$ are presented with a heatmap. Lower $P$ values are shown in dark purple, and higher $P$ values are light purple. Nonsignificant pathways are presented in gray. (B) Volcano plot of non-differentially expressed genes (NDEGs) from SARS-CoV-2-infected cells. The orange dots represent NDEGs with an absolute $\log _{2}$ (fold change) $\leq 1$ or a $P$ value $\geq 0.05(n=2)$ compared with the control. For the small sample number, the $P$ value was calculated with Limma-voom R package following the method reported by Ritchie ME et al. [48]. (C) Venn diagram showing the overlap of non-differentially expressed genes (NDEGs) in the transcriptional data and differentially expressed proteins (DEPS) $\left(P\right.$ value $<0.05$ and absolute $\log _{2}$ (fold change) $>1$ ) in the translational data $(n=3)$. (D) 
Analysis of GO terms for the 192 proteins shared by NDEGs and DEPs with $P$ value < 0.05 . (BP: Biological Process; CC: Cellular Component; MF: Molecular Function) (E) The time-dependent expression of SARS-COV-2 proteins detected by proteomics.

Table 1. SARS-CoV-2-related proteins and their corresponding top 10 coexpressed host proteins in blue module.

\begin{tabular}{cl}
\hline $\begin{array}{c}\text { SARS-CoV-2-related } \\
\text { proteins }\end{array}$ & Corresponding top 10 coexpressed host proteins \\
\hline $\mathrm{N}$ & PP1A, KRT18, TMBIM6, ORF9b, TFRC, S, KRT8, RAB5C, SCD \\
ORF3a & TMBIM6, ORF9b, PP1A, KRT8, KRT18, RAB5C, TFRC, IPO7, MTHFD1L, EEF1B2 \\
ORF9b & TMBIM6, SLC3A2, PP1A, IPO7, ORF6, APLP2, RAB5C, STAG1, KRT18, ZC3HAV1 \\
PP1A & SPC25, LRP1, TFRC, TMBIM6, SELENOS, SLC3A2, TKT, CYP51A1, HLA-B, IDI2 \\
ORF6 & PP1A, SLC3A2, TMBIM6, HLA-B, IDI2, SELENOS, PGPEP1, SPC25, TFRC, CYP51A1 \\
S & TMBIM6, PP1A, ORF9b, ANXA13, KRT18, RAB5C, TFRC, KRT8, ORF6, ECH1 \\
\hline
\end{tabular}

and so on (Figure 1D). And Daniloski et al. [18] identified that SARS-CoV-2 infection negatively downregulates the cholesterol synthesis pathway and viral infection can be counteracted by drug treatments that upregulate the same pathway, which is consistent with our results. In parallel, we also performed intersection analysis to identify the overlap of proteins encoded by DEGs and DEPs in Caco2 cells infected with SARS-CoV-2, and the results are displayed in (Supplementary Figure 1). The results indicating that host cells may influence the expression of related proteins, catabolic process, metabolic process and other related pathways through the regulation at the transcriptional level.

\section{Identification of SARS-CoV-2-related protein modules through WGCNA}

In the article of Bojkova et al., we found that the morphology of host cells changed significantly 24 hours after infection, indicating that virus infection had a great impact on cells (Figure 1E). We therefore performed dimensional reduction with weighted gene co-expression network analysis, which is robust for small sample sizes, reduces the burden of multiple hypothesis testing, identifies clusters or networks of proteins that are potentially dysregulated, and analyzes the relationship between protein coexpression pattern and cell phenotype after virus infection. Also, several studies $[19,20]$ used WGCNA to analyze gene expression during virus infection. A total of twenty-three modules were identified by setting the soft-thresholding power as 8 (scale-free $\mathrm{R}^{2}=$ 0.85) (Figure 2A), cut height as 0.25 , minimal module size as 50 and threshold as 0.2 (Figure 2B). From the heatmap of module-trait correlation (Figure 2C), we found two modules, blue module and turquoise module, significantly correlated $(P<0.01)$ with virus amplification according to the corresponding correlation and $P$ value (Figure 2D-2E). The expression of proteins in the module may be upregulated or down-regulated. ClueGO was then used to reveal the potential biological processes of proteins in the blue and turquoise modules. The results demonstrated that the blue module proteins had a close relationship with cholesterol biosynthesis process, positive regulation of sterol transport and negative regulation of response to ERS (Figure 2G), which is also consistent with our previous findings, and the turquoise module proteins were closely related to the regulation of hydrolase activity, $\mathrm{T}$ cell activation and liquid metabolic process (Figure 2F).

\section{The regulatory relationship between SARS-CoV-2 proteins and host proteins}

In the WGCNA results, we noted that six viral proteins were clustered in the blue module, suggesting that those viral proteins play an important role in the amplification of SARS-CoV-2 in the cells. After analyzing the weights between the paired proteins with GENIE3, we obtained the close regulatory relationships between viral proteins and host proteins in the cells. The top $0.2 \%$ (77 pairs) of the 38281 related pairs were chosen for further analysis, and we found that these paired proteins were selectively associated with ORF3a (Figure 3A), PP1A (Figure 3B) and ORF6 (Figure 3C). Intriguingly, ORF3a had a higher weight in regulating host proteins than other viral proteins, indicating an important role of ORF3a in the replication of SARS-CoV-2 in the cells. GO enrichment analysis demonstrated that ORF3a, PP1A and ORF6 were functionally related to ER organization and macroautophagy (Figure 3D), autophagosome (Figure 3E) and glucose catabolic process (Figure 3F), respectively. Due to the relatively low weights of $\mathrm{S}, \mathrm{N}$ and ORF9b for regulating host proteins, the top 30 host proteins regulated by these proteins were chosen for $\mathrm{GO}$ enrichment analysis (Supplementary Figure 2A-2C). GO enrichment analysis demonstrated that $\mathrm{S}, \mathrm{N}$ and ORF9b were functionally related to metabolic pathway (Supplementary Figure 2D), inflammatory response (Supplementary Figure 2E) and cell cycle (Supplementary Figure 2F), respectively. The functional domains of the viral proteins are also displayed in (Supplementary Figure 3) to provide a preliminary understanding of the structure of SARS-CoV-2 viral proteins. 
Identification of hub proteins in the blue and turquoise modules

Since SARS-CoV-2-related proteins were found to be mainly clustered in the blue module, we selected the top 10 host proteins coexpressed with each viral protein in the blue module, as shown in (Table 1). Interestingly, we found that TMBIM6 showed prominent coexpression with all viral proteins identified in the blue module, indicating that TMBIM6 is a key element influenced by the infection of SARS-CoV-2 in the cells (Figure 4A). Previous studies have reported that TMBIM6 acts as a BAX inhibitor by blocking BAX translocation from the

A

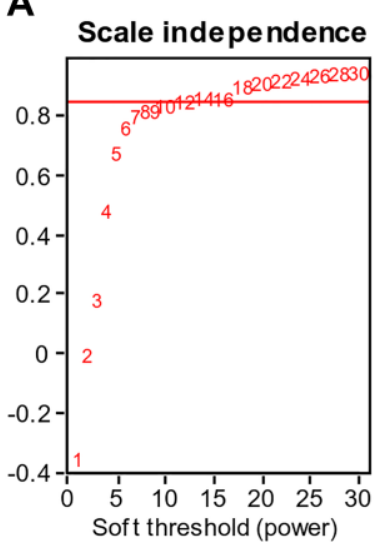

C

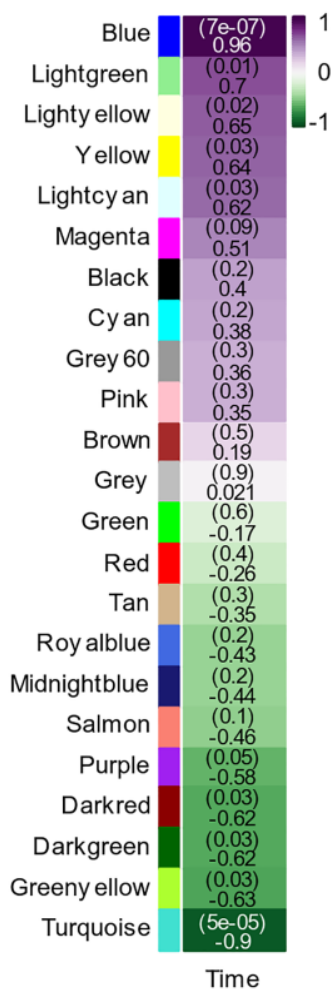

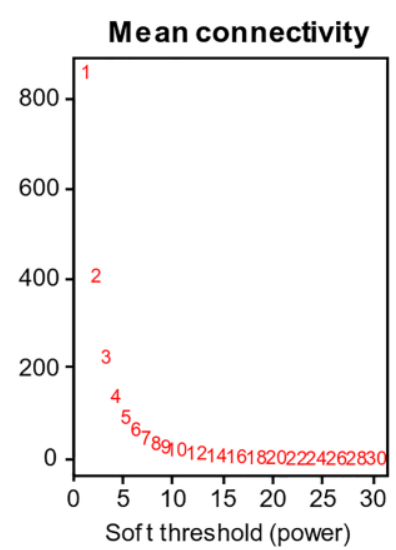

D

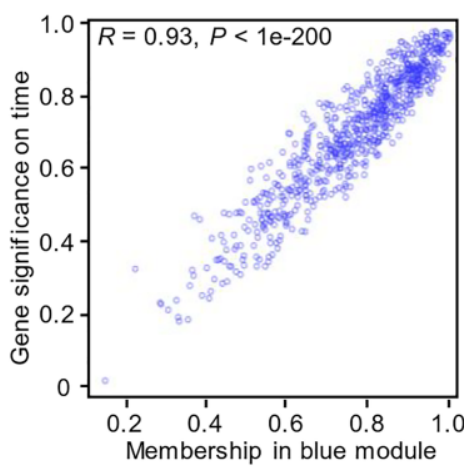

E

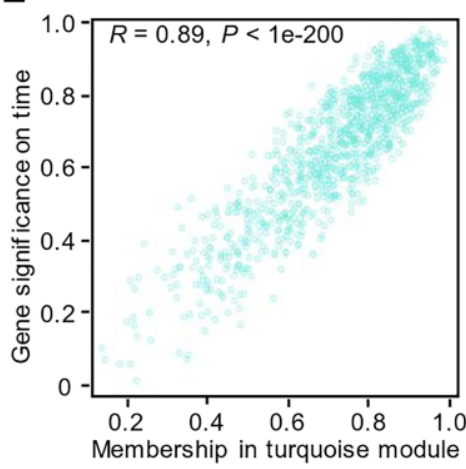

ER to mitochondria [21, 22]. We found that BAX [23] was in the turquoise module, which was in contrast to the blue module and related to the cellular stress response. Thus, we identified TMBIM6 as a hub protein in the blue module associated with viral proliferation.

\section{Multiomics data analysis of the expression of TMBIM6}

To determine whether the regulation of TMBIM6 expression occurred at the posttranscriptional level, we performed systematic studies on the expression of

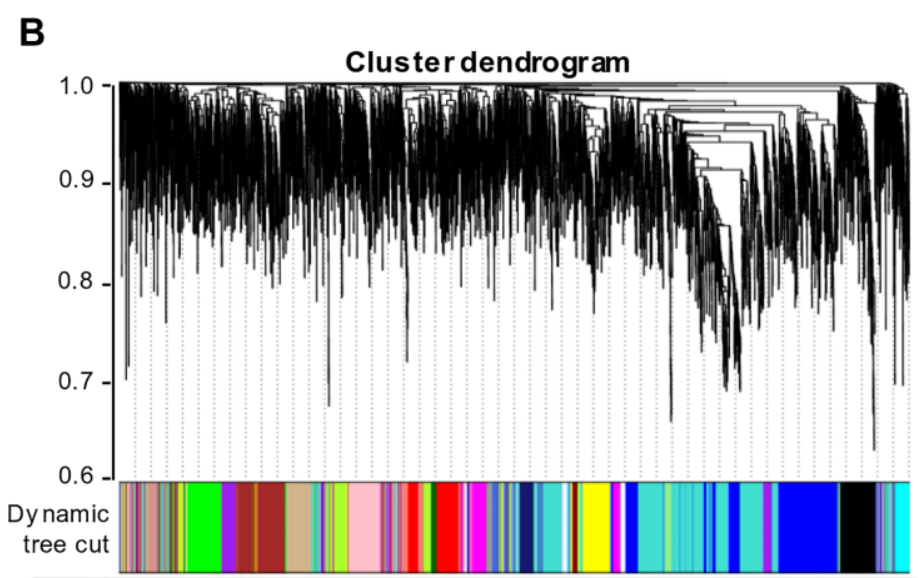

$\mathbf{F}$

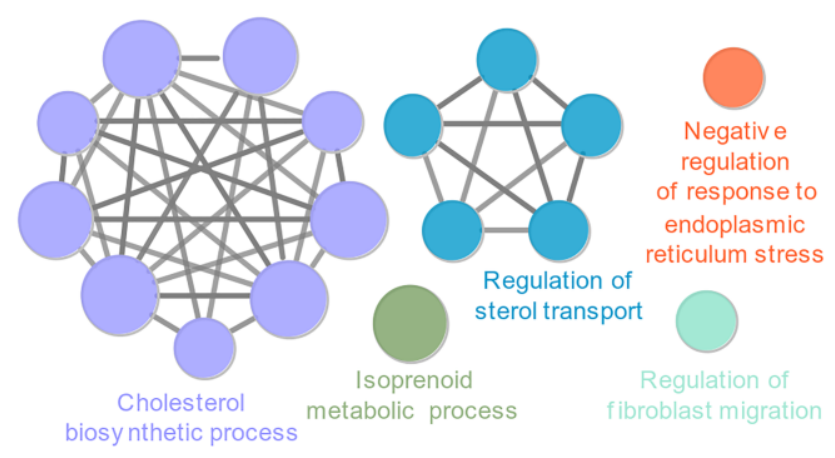

G

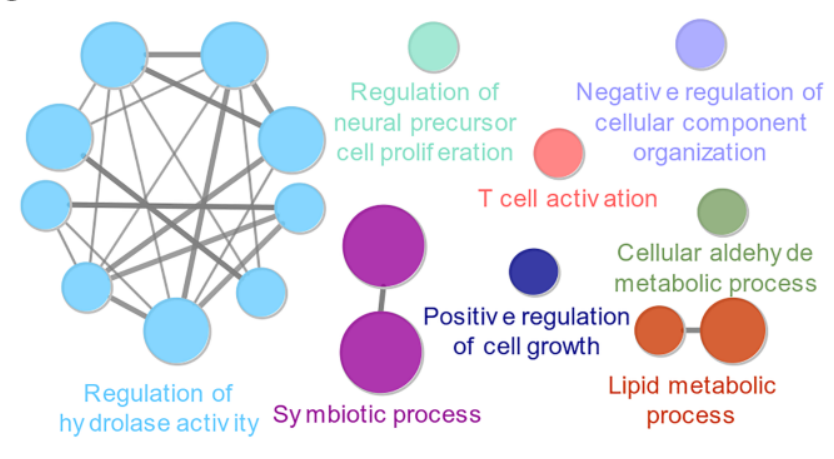

Figure 2. Identification of key modules through WGCNA of the proteomics data. (A) Analysis of the scale-free fit index (left) and the mean connectivity (right) for various soft-thresholding powers. (B) Clustered dendrogram of the top 5000 proteins based on the 
dissimilarity measure. (C) Heatmap of the correlations between modules and virus amplification over time. Each cell contains the correlation coefficient and $P$ value. (D) The corresponding correlation and $P$ value between proteins in the blue module and virus amplification over time. (E) The corresponding correlation and $P$ value between proteins in the turquoise module and virus amplification over time. (F) Enrichment analysis of the proteins in the turquoise module with $P$ value $<0.05$. (G) Enrichment analysis of the proteins in the blue module with $P$ value $<0.05$.

TMBIM6 with publicly available transcriptome (Figure 4B), translatome (Figure 4C) and proteome (Figure 4D) data from Caco-2 cells infected with SARS-CoV-2. From the transcriptome data, we found that there was no significant difference in the expression of TMBIM6 in Caco-2 cells during infection with SARS-CoV-2 for
$24 \mathrm{~h}$ at the transcriptional level (Figure 4B). However, there was a significant decrease in TMBIM6 at both the translatome and proteome levels in $24 \mathrm{~h}$. To certify that this phenomenon was specifically induced by SARSCoV-2, we performed expression analysis with translatome and proteome data from mock-infected

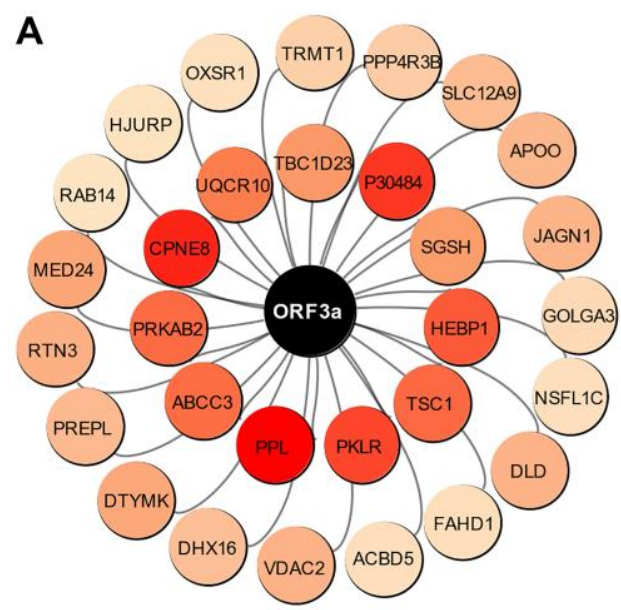

D
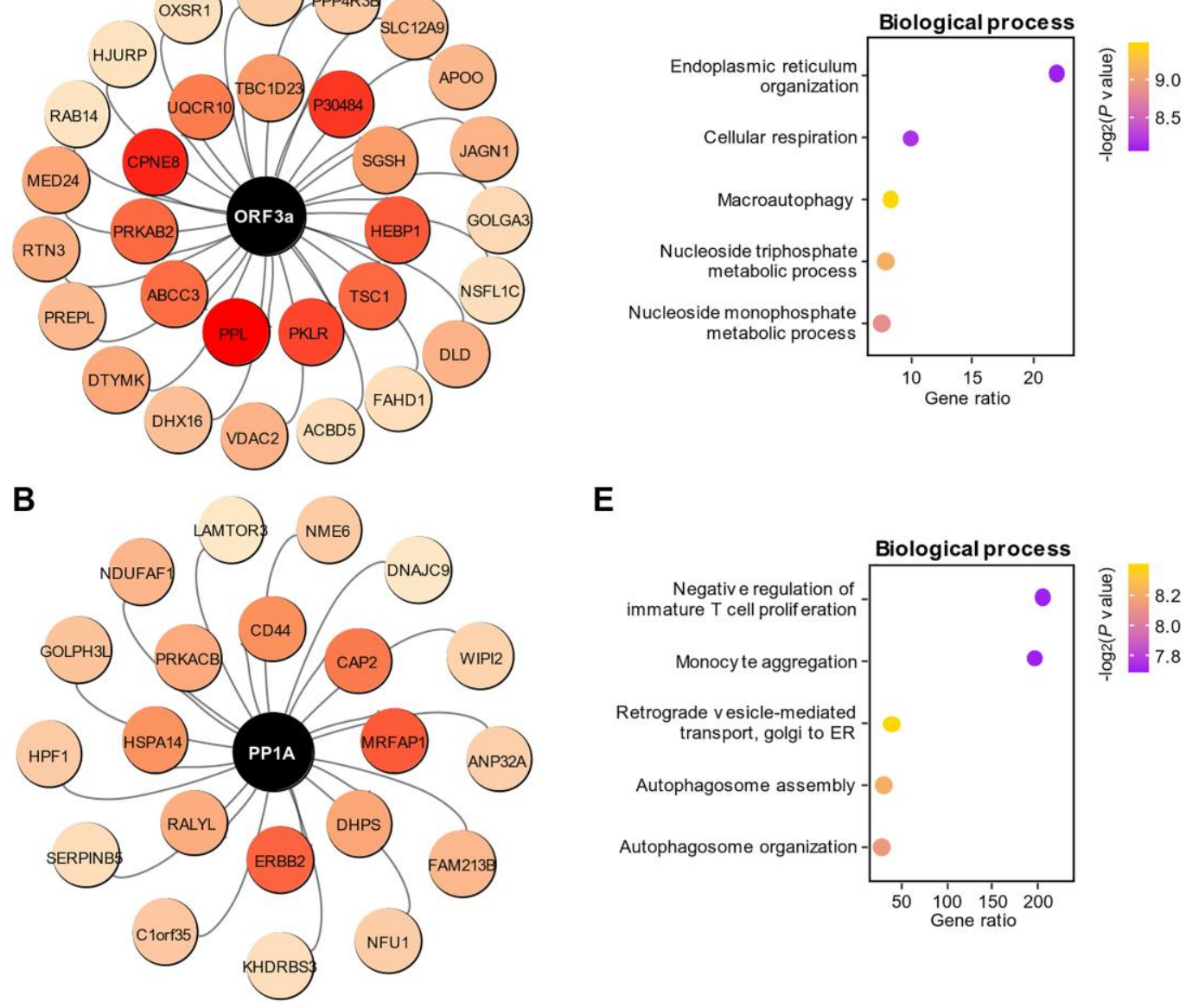

E

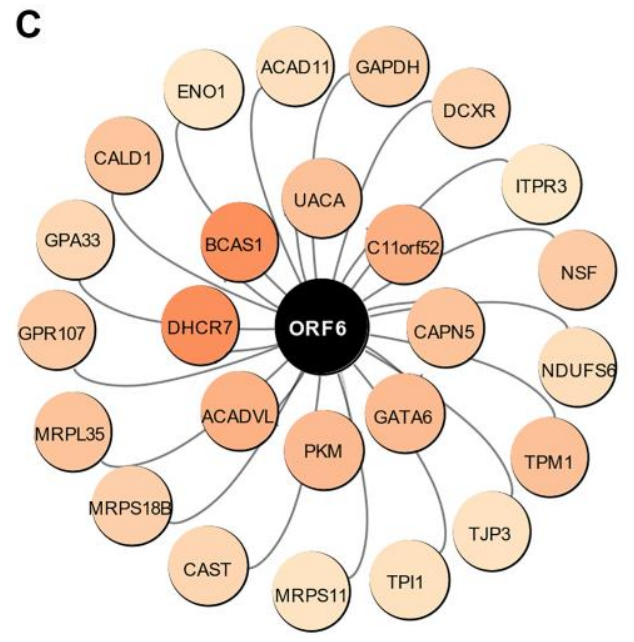

$\mathbf{F}$
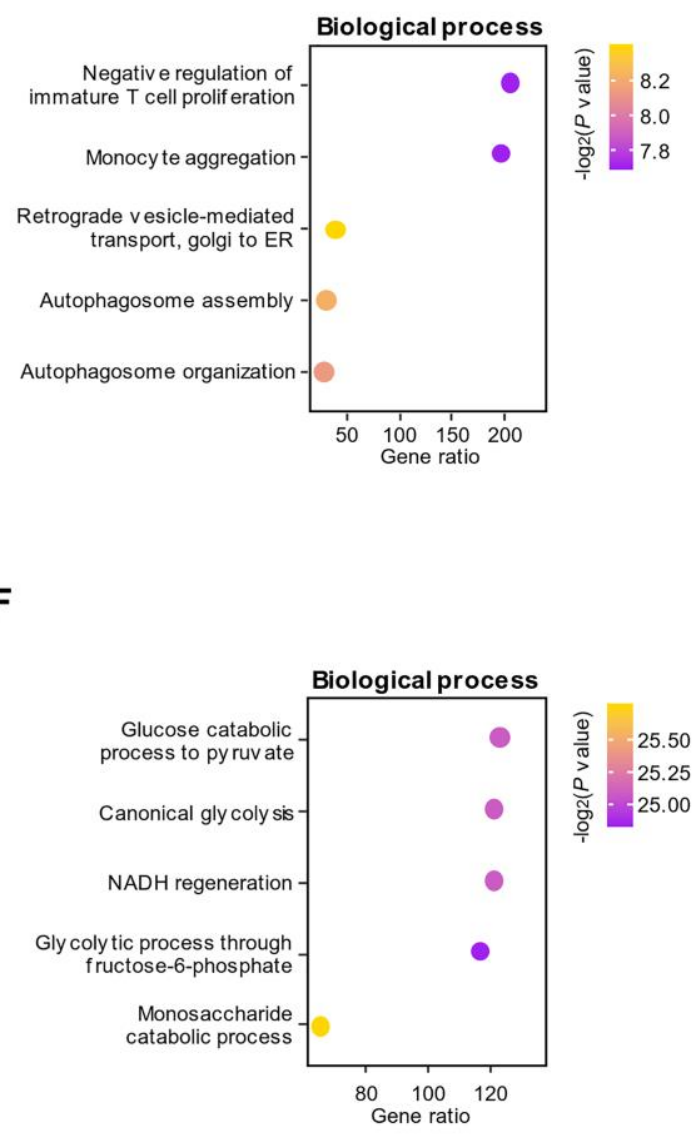
Figure 3. Functional prediction of viral proteins in the blue module. $(\mathbf{A}-\mathbf{C})$ The paired associations of the top three viral proteins, ORF3a (A), PP1A (B) and ORF6 (C), with high-weight host proteins in the regulation predicted by GENIE3. The color depth represents the weight of the pairing between viral proteins and each host protein. (D-F) Enrichment of biological processes associated with host proteins regulated by the viral proteins ORF3a (D), PP1A (E) and ORF6 (F).

Caco- 2 cells as the control and found that there was no significant difference in the expression of TMBIM6 during the $24 \mathrm{~h}$ observation period (Supplementary
Figure 4A-4C). The heatmap displayed clustered proteins with an expression pattern similar to that of TMBIM6 in the translatome data (Figure 4E). The
A

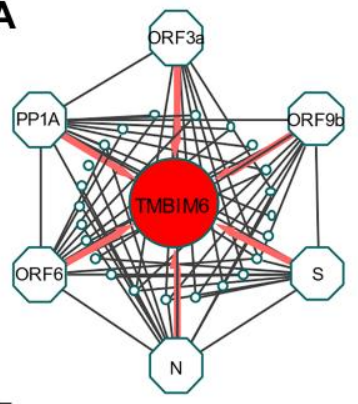

E

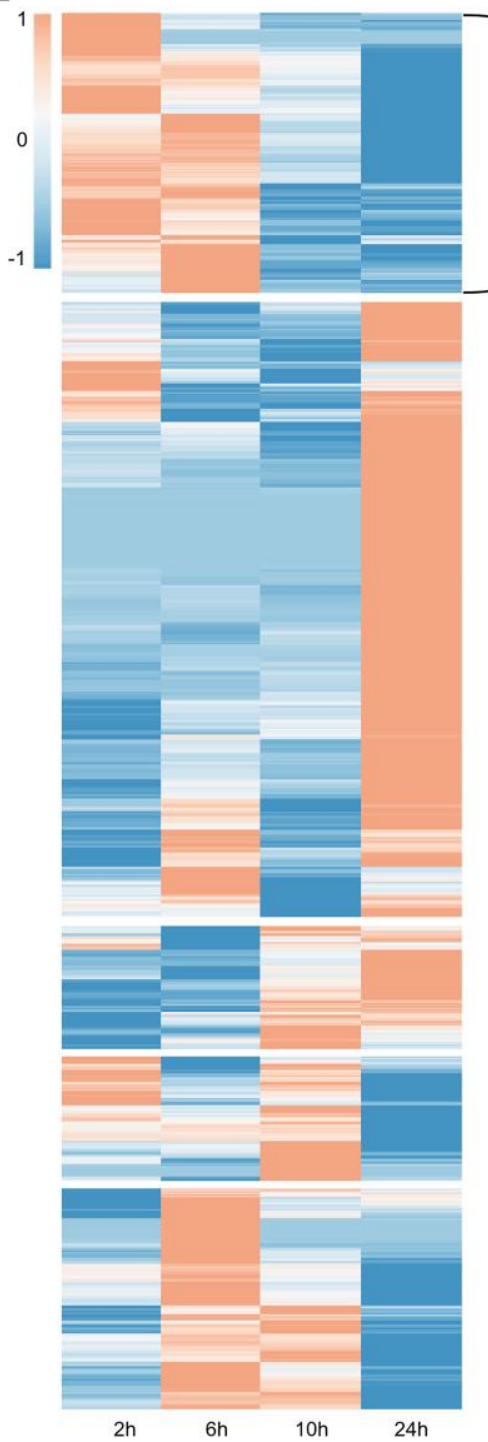

B

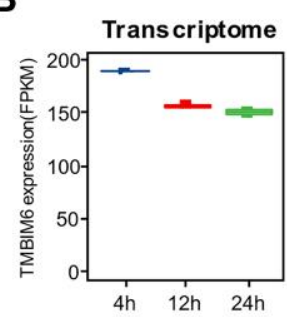

C

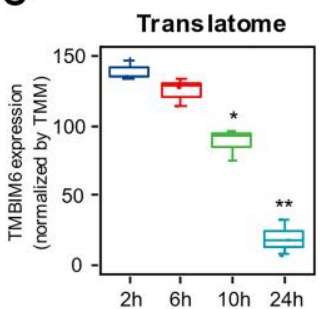

D

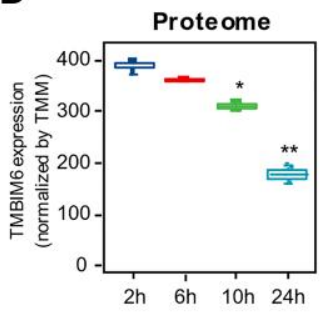

F

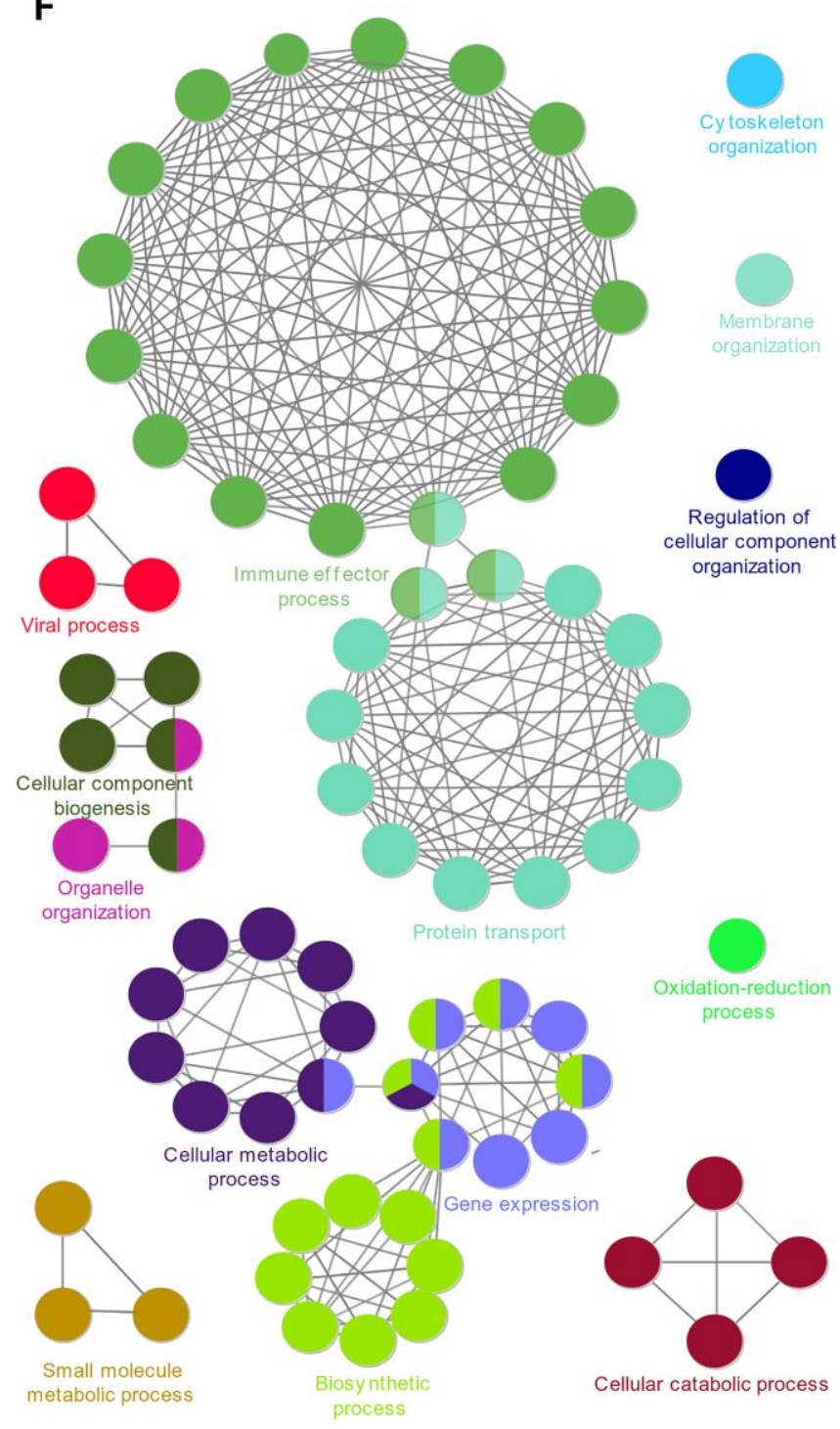


Figure 4. Identification of the host protein TMBIM6 as a potential target for viral pathogenesis. (A) Top 10 coexpression relationships of SARS-COV-2 proteins, including PP1A, S, ORF3a, ORF6, ORF9b and $\mathrm{N}$, and host proteins from the blue module. TMBIM6 was found to be coexpressed with these six viral proteins. (B-D) The expression of TMBIM6 at different times based on multiomics data from SARS-CoV-2-infected cells. $n=3,{ }^{*} P$ value $<0.05,{ }^{* *} P$ value $<0.001$. (E) Heatmap of expression clustering for proteins from the translational data. The cluster with an expression pattern similar to TMBIM6 was selected for the next step of analysis. (F) Enrichment analysis of biological processes of proteins from the selected cluster with $P$ value $<0.05$.

results of GO enrichment analysis revealed that the proteins in this cluster were related to the viral process, immune effector and biosynthesis process (Figure 4F). Further enrichment analysis of the proteins coexpressed with TMBIM6 demonstrated that TMBIM6 might be related to metabolic processes and chaperone-mediated protein folding (Supplementary Figure 5).

\section{Expression of TMBIM6 in different human tissues and A549 cells infected with SARS-CoV-2}

To verify the results above, we found another multiomics data to see the expression of TMBIM6. Analyzing the gene expression of TMBIM6 in autopsied lung tissues (Figure 5A) and we found that 
A

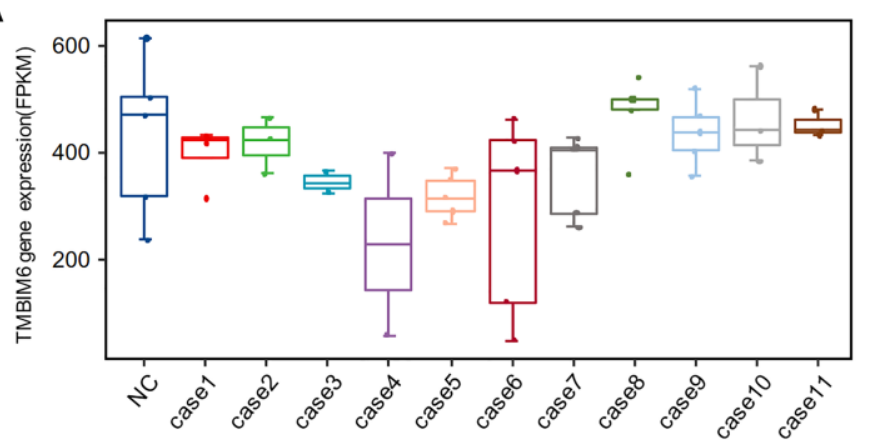

B

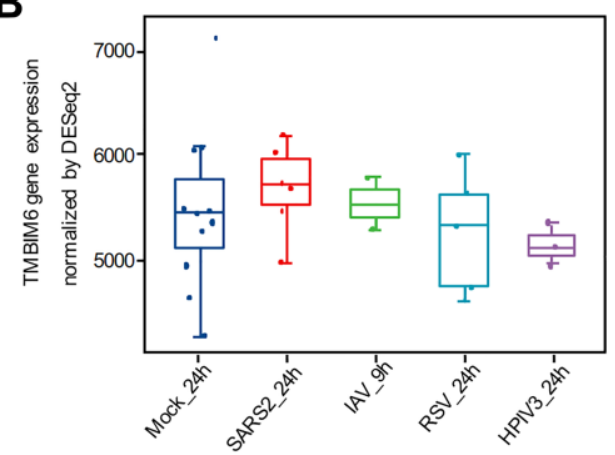

C

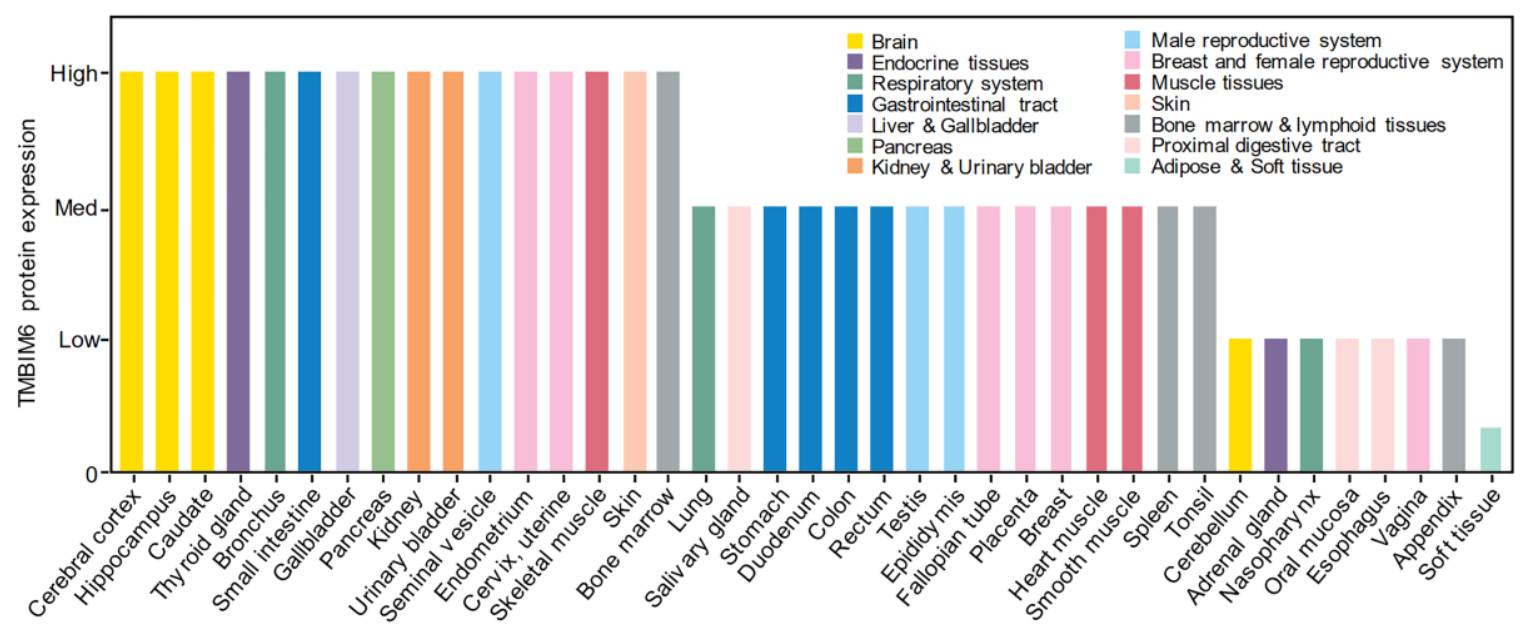

D

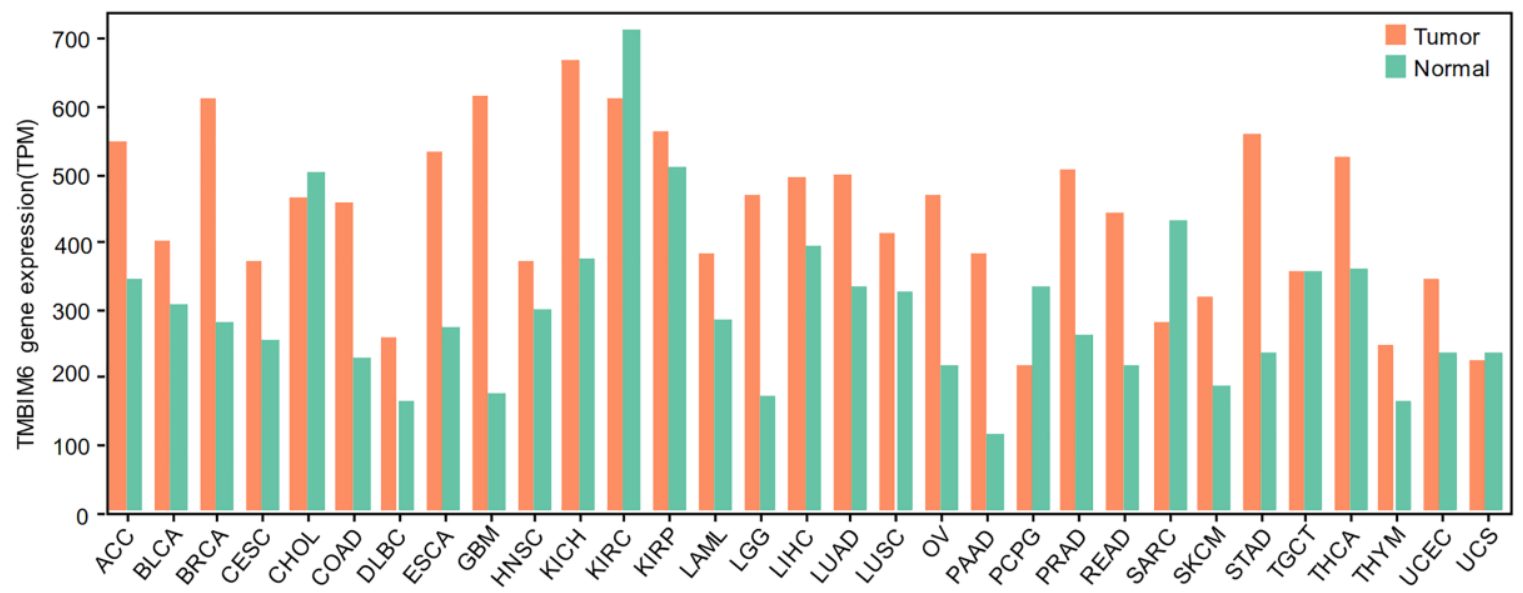

Figure 5. The expression of TMBIM6 in different human tissues and A549 cells infected with different viruses. (A) Nondifferential expression for TMBIM6 gene in autopsied lungs from patients who died from SARS-CoV-2 infection. (In all the cases, $P$ value $>0.05$, comparison to negative control). (B) Nondifferential expression for TMBIM6 gene in cells infected with different viruses at $24 \mathrm{~h}$ or $9 \mathrm{~h}$. ( $P$ value $>0.05$, comparison to mock control). (C) The protein expression of TMBIM6 in different human tissues from the HPA database. (D) The gene expression of TMBIM6 in tumor and normal tissues from the GEPIA2 database at the transcriptional level.

Table 2. Statistical analysis of TMBIM6 protein changes at 3, 6, 12, 18, 24 and $30 \mathrm{~h}$.

\begin{tabular}{ccc}
\hline Time points & Log2Foldchange & $\boldsymbol{P}$ value \\
\hline $3 \mathrm{~h}$ & -0.014587327 & 0.847830887 \\
$6 \mathrm{~h}$ & -0.046795833 & 0.767755994 \\
$12 \mathrm{~h}$ & -0.132258938 & 0.598284486 \\
$18 \mathrm{~h}$ & -0.727420294 & 0.064174941
\end{tabular}


there was no significant difference in TMBIM6 expression at the transcriptional level. The results of the transcriptome analysis of cells invaded by different viruses showed that the gene expression of TMBIM6 was not significantly downregulated by SARS-CoV-2 or other viruses (Figure 5B). Moreover, we analysed Alexey Stukalov's SARS-CoV-2-infected proteome data, which displays that TMBIM6 protein has a downward trend at the proteome level, as shown in the (Table 2). We also got differentially expressed proteins information of IAV infection from Coombs et al. (Supplementary Table 1) and that of RSV infection from Sande et al. (Supplementary Table 2), and both of them showed that TMBIM6 protein was not differentially expressed before and after infection with IAV and RSV.

To clarify the gene and protein expression of TMBIM6 in different human tissues, we performed expression analysis using the Human Protein Atlas (HPA) and Gene Expression Profiling Interactive Analysis (GEPIA2) and found that the TMBIM6 protein was highly expressed in most human tissues, including the brain, bronchus, kidney, small intestine, lung, and heart muscle (Figure 5C), and that the TMBIM6 gene was highly expressed in most human tissues at the transcriptional level, as well as tumors (Figure 5D).

\section{DISCUSSION}

SARS-CoV-2 is currently the most harmful public health disaster. Previous studies have mainly focused on receptors for the spike protein of SARS-CoV-2, especially ACE2. In contrast, few studies have focused on multiomics data from cells infected with SARSCoV-2. To date, the intracellular mechanism that is utilized by the virus to achieve replication in host cells is largely unknown. To gain insight into the activation of signaling pathways in SARS-CoV-2-infected cells, we acquired proteome data to perform GSEA. The GSEA results demonstrated that SARS-CoV-2 influenced the regulation of many signaling pathways, including the ErbB, PI3K-AKT, HIF-1 and Rap1 signaling pathways, in host cells, which was consistent with the findings of Appelberg et al. [17]. We also found that SARS-CoV-2 infection was involved in signaling pathways associated with metabolic processes, including glycolysis/gluconeogenesis, fatty acid metabolism and carbon metabolism, and protein processing in the ER. These results suggest that by utilizing intracellular mechanisms, SARS-CoV-2 completes virus replication, which leads to metabolic disorders and the ERS response in host cells.

To understand SARS-CoV-2's influence on cells at the post-transcriptional level, and remove some of the stress responses made by host cells at the transcriptional level due to SARS-CoV-2's invasion, we performed a combined analysis of proteins encoded by NDEGs and DEPs to identify the overlapping proteins in Caco-2 cells infected with SARS-CoV-2. The time-dependent expression of viral proteins represents virus replication in the cells; thus, we performed WGCNA on the proteome data to identify host proteins influenced by SARS-CoV-2. Intriguingly, the blue and turquoise modules were identified significantly correlated $(P<$ $0.01)$ with virus amplification. Six viral proteins of SARS-CoV-2 were found to be clustered in the blue module, indicating that those viral proteins play an important role in the amplification of SARS-CoV-2 in host cells. The GENIE3 results showed that in comparison with other viral proteins, ORF3a had the highest weight for the regulation of host proteins, indicating that ORF3a plays an important role in the replication of SARS-CoV-2 in host cells. Previous studies on SARS-CoV have reported a prominent reduction of the virus following ORF3a deletion [24], and ORF3a was proposed to utilize multiple pathways to promote apoptosis in virus-infected cells [25]. Further analysis of GO enrichment showed that the main function of ORF3a was related to ER organization and macroautophagy, which was consistent with the results reported by Freundt et al. [26]. The results obtained for other viral proteins were also supported by several previous studies. For example, PP1A was reported to play a role in the initial induction of autophagosomes from the ER and in signaling pathways modulating the survival of host cells [27-29]. The latest study reported that ORF6 led to disordered metabolic molecular markers in the blood of SARS-CoV-2 patients [30]. As shown in (Table 1), the top ten proteins coexpressed with the viral proteins in the blue module demonstrated that TMBIM6 showed prominent coexpression with all detectable viral proteins, indicating that TMBIM6 is a key element influenced by the infection of SARS-CoV-2 in the cells. To determine whether the regulation of TMBIM6 expression occurred at the posttranscriptional level, we performed systematic studies on the expression of TMBIM6 with open access transcriptome, translatome and proteome data. Interestingly, we found that there was no significant difference in the expression of TMBIM6 at the transcriptional level; in contrast, there was a 
significant decrease in the expression of TMBIM6 at posttranscriptional levels, including both the translatome and proteome levels (Figure 4B-4D).

To certify that this phenomenon was induced by replication of SARS-CoV-2, we performed an analysis of multiomics data from mock-infected Caco-2 cells and found that the mock failed to downregulate the expression of TMBIM6 at both the mRNA and protein levels (Supplementary Figure 4A-4C). The idea that TMBIM6 is influenced by SARS-CoV-2 at the posttranscriptional level is also supported by several lines of evidence. For example, TMBIM6 expression was not significantly different in autopsied lung tissues from deceased COVID-19 patients at the transcriptional level. Consistently, the results obtained with the multiomics data from SARS-CoV-2-, IAV- or RSV-invaded cells demonstrated that TMBIM6 protein was specifically downregulated by SARS-CoV-2 but not other viruses at the posttranscriptional level. In comparison with other respiratory viruses, SARSCoV-2 was found to have a high infection rate. We speculate that SARS-CoV-2 has specific targets that are different from those of other respiratory viruses and that TMBIM6 is an important potential target influenced by SARS-CoV-2 in host cells.

To date, the mechanism by which SARS-CoV-2 regulates the translation and synthesis of host proteins has not been clearly defined. For the decreased protein expression of TMBIM6 in the cells infected with SARS-CoV-2, we considered two aspects to provide a reasonable explanation. On the one hand, host protein translation is restrained by the competition of viral proteins, resulting in decreased expression of host proteins. For example, Bojkova et al. reported that viral proteins compete with host proteins for efficient translation [10]; Thoms et al. reported that nonstructural protein 1 (nsp1), a major virulence factor of SARSCoV-2, suppresses host protein expression by ribosome association [31]. Additional analysis of SARS-CoV-2 also supports this idea; Alonso et al. reported that the preferred codons of SARS-CoV-2 have poor representation of $\mathrm{G}$ and $\mathrm{C}$ nucleotides in the third position, which could lead to an imbalance in the tRNA pools of the infected cells, with serious implications for host protein synthesis [32]. Based on these findings and our results, we speculate that the translation of six viral proteins leads to inefficient translation of host protein TMBIM6. Similar to nsp1, the six viral proteins may also inhibit the translation of TMBIM6 by binding to ribosomes. The consumption of specific tRNAs for the replication of the six viral proteins may restrict the synthesis of host proteins. On the other hand, the intracellular mechanisms controlling protein synthesis in host cells are hijacked by SARS-CoV-2 for massive synthesis of viral proteins, which leads to the accumulation of more misfolded and unfolded proteins, including TMBIM6, in the ER cavities. Subsequently, the unfolded protein response (UPR) occurs, and the host cells may stop protein translation or degradation of misfolded proteins to restore homeostasis and cell function.

TMBIM6 is a multifunctional protein with the ability to inhibit the function of viral genes, attenuate UPR and ER stress [33], regulate calcium release [34], reduce the production of reactive oxygen species (ROS) [35, 36], activate Bcl-2 and inhibit BAX [37]. Previous studies demonstrated that the TMBIM6 protein is involved in the regulation of cellular responses to influenza virus infection by inhibiting the function of viral genes. For example, overexpression of TMBIM6 in MDCK cells impaired influenza virus production, viral propagation, and the synthesis of viral genes; MDCK cells overexpressing TMBIM6 were more resistant to influenza virus infection and virus-induced cell death [38]. Based on the results of bioinformatics analysis, we speculate that the decrease in the protein expression of TMBIM6 promotes continuous activation of the UPR. Under pathophysiological conditions, the UPR activates corresponding signaling pathways to produce more molecular chaperones for protein folding, and it is also possible that the UPR is utilized by SARS-CoV-2 to increase the assembly capacity of the ER to meet the protein synthesis needs of viral replication, thus promoting new virion assembly and the release of SARS-CoV-2 from infected cells. As described in the working model which was created by BioRender in (Figure 6), the balance of $\mathrm{Ca}_{2}{ }^{+}$in the ER is disrupted, and ROS induced by SARS-CoV-2 cannot be controlled effectively due to the lack of the TMBIM6 protein, leading to an increase in $\mathrm{Ca} 2^{+}$concentrations and accumulation of ROS in mitochondria. Consequently, the increase in mitochondrial permeability causes the release of proapoptotic factors and the activation of BAX, leading to host cell apoptosis. Other lines of evidence also support the idea that TMBIM6 plays an important role during SARSCoV-2 infection. The data of Alex et al. indicated that SARS-CoV $\mathrm{S}$ protein-induced membrane fusion is dependent on calcium [39] and Marco et al. reported that calcium channel blockers inhibited SARS-CoV-2 infectivity [40]. So, we infer that the decrease in the TMBIM6 expression leads to the disorder of $\mathrm{Ca}^{2+}$ concentration, which promotes the infection of SARSCoV-2. Although the prominent clinical symptoms of SARS-CoV-2 are lung related [41], the impact of SARS-CoV-2 on other tissues has also gradually been uncovered; several recent studies have revealed that SARS-CoV-2 infects various organs, such as the brain 
[42], heart [43], gastrointestinal tract [44] and kidney [45], in addition to the lung. Consistently, in the HPA database, the TMBIM6 protein was highly expressed in most human tissues, including the brain, heart muscle, lung, bronchus, small intestine, kidney, etc. Recently, it was reported that cancer patients infected with SARS-CoV-2 have a higher risk of severe events and a poorer prognosis than those without cancer [46]. Through analysis of the GEPIA2 database [47], we found that the TMBIM6 transcription level was even higher in most cancers. These results suggest that SARS-CoV-2 may damage various organs by downregulating the expression of TMBIM6 protein, and may also affect the prognosis of cancer patients.

In summary, by performing bioinformatics analysis of multiomics data, we identified TMBIM6 as a potential viral regulatory protein in SARS-CoV-2infected cells. However, our study has some limitations, such as a lack of experimental evidence, especially in vivo results to confirm our findings, because the highgrade BSL facility at our institution was inaccessible. Chemical compound screening and drug design targeting TMBIM6 might provide a novel clinical approach for the treatment of COVID-19 in the future.

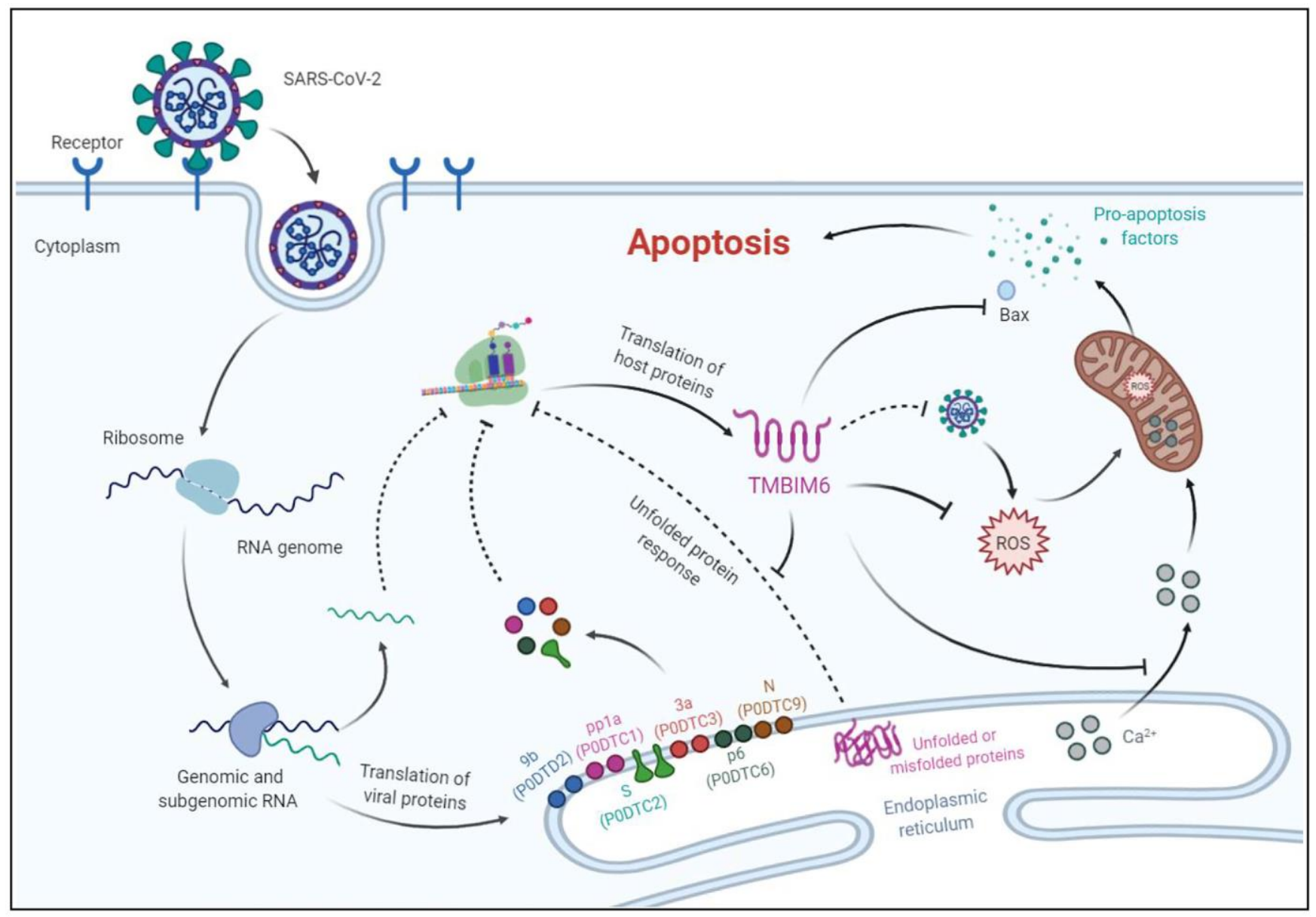

Figure 6. A proposed working model for the apoptosis of host cells infected with SARS-CoV-2. Possible mechanisms of host cell apoptosis induced by SARS-CoV-2 through translational inhibition of TMBIM6. TMBIM6 is a multifunctional protein that can inhibit the activation of BAX, ROS production and $\mathrm{Ca}^{+}{ }^{+}$release from the ER. Upon SARS-CoV-2 infection, downregulated TMBIM6 promotes the release of $\mathrm{Ca}^{+}$and ROS accumulation in mitochondria, which leads to the release of proapoptotic factors. In addition, downregulation of TMBIM6 relieves its inhibition of BAX activation, thus leading to host cell apoptosis.

\section{MATERIALS AND METHODS}

\section{Differential gene and protein expression analysis}

Differential gene expression analysis was performed with Limma-voom (version 3.42.0) [48] to compare gene expression in SARS-CoV-2-infected cells at different times using the transcriptome data of Emanuel et al. [11]. For the small sample number [48], we considered genes with a $P$ value, rather than $\mathrm{Q}$ value, < 0.05 and an absolute value of $\log _{2}$ (fold change) $>1$ as DEGs; conversely, genes with a $P$ value $\geq 0.05$ or an absolute value of $\log _{2}$ (fold change) $\leq 1$ were considered non-differentially expressed genes (NDEGs). Also, 
through the transcriptome data of autopsied lungs, we utilized Limma-voom to calculate statistic difference and conform the expression of TMBIM6 at the transcriptional level. As for the transcriptome data of different virus-infected A549 cells, we utilized Deseq2 to calculate the statistic difference of the expression of TMBIM6 according to the original author. Similarly, using the proteome and translatome data of Bojkova et al. [10], differentially expressed proteins (DEPs) and non-differentially expressed proteins (NDEPs) were defined by statistical analysis with two-sided unpaired student's t test with equal variance assumed according to the original author. $P$ value $<0.05$ and an absolute value of $\log _{2}$ (fold change) $>1$ were regarded as the cutoff criteria.

\section{Gene set enrichment analysis}

To gain insight into the activation of signaling pathways in SARS-CoV-2-infected cells, we performed GSEA on the proteome data with the "clusterProfiler" [49] and "GSEABase" [50] R packages. In details, gene set size $>5$ and $<500$, and $P$ value $<0.05$ were regarded as the cut-off criteria. Protein expression at 2, 4, 10 and $24 \mathrm{~h}$ was compared between SARS-CoV-2-infected cells and mock-infected cells, respectively.

\section{Protein coexpression network analysis}

The R package WGCNA [51] was applied to find clinical trait-related modules and hub proteins within those modules using the proteome data of Bojkova et al. According to the topological overlap matrix (TOM)-based dissimilarity measure, proteins were divided into different modules. Here, we set the soft-thresholding power as 8 (scale-free $\mathrm{R}^{2}=0.85$ ), cut height as 0.25 , minimal module size as 50 and threshold as 0.2 to identify key modules. Modules with the highest and lowest correlations with virus amplification over time were selected to explore their biological functions through ClueGO analysis. Hub proteins were defined as those coexpressed with virus proteins in the selected modules.

\section{Functional enrichment analysis}

To further understand the mechanism of cellular processing, we conducted GO enrichment analysis using the Cytoscape [52] software "ClueGO" [53], "WEB-based GEne SeT Analysis Toolkit" (WebGestalt) [54] and R package "clusterProfiler" [49]. GO terms with a $P$ value $<0.05$ were considered statistically significant and visualized with the "ClueGO" and "ggplot2" R packages [55, 56].

\section{Gene regulatory network analysis}

GENIE3 [57, 58] is an algorithm to infer gene regulatory networks from protein expression data. As for weight, the official document states that the choice of weight is like this: "The weights of the links returned by GENIE3() do not have any statistical meaning and only provide a way to rank the regulatory links. There is therefore no standard threshold value, and caution must be taken when choosing one." Moreover, in the example of official documents, weight $>0.1$ is selected as the screening standard. But for our data, there are too many proteins screened out by this standard, so we want to screen the appropriate number according to a certain proportion. We try a variety of screening methods and finally take the top $0.2 \%$. According to this standard, we get the relationship between three virus proteins and host proteins. There are six virus proteins interacting with host proteins, and we just got 3 virus proteins at the top $0.2 \%$ ( 77 proteins). The weight between the other three virus proteins and host proteins is low. It is difficult to screen according to a certain proportion, so we selected the top 30 host proteins regulated separately by the remaining three virus proteins to do enrichment analysis.

\section{Analysis of protein expression in human tissues}

The HPA [59] aims to map all human proteins in cells, tissues and organs by integrating various omics technologies, including antibody-based imaging, mass spectrometry-based proteomics, transcriptomics and systems biology. The HPA database was used to search the TMBIM6 protein expression in most tissues.

\section{Analysis of mRNA expression}

Following a standard processing pipeline, GEPIA2 [47] was used to analyze RNA sequencing data for 9,736 tumors and 8,587 normal samples from TCGA and GTEx projects. The TMBIM6 expression profile at the transcriptional level was characterized with GEPIA2 across all tumor samples and paired normal tissues.

\section{Data and materials availability}

All data associated with this study are presented in the paper.

\section{Abbreviations \\ COVID-19: Coronavirus disease 2019; SARS-CoV-2: severe acute respiratory syndrome coronavirus 2; GSEA: gene set enrichment analysis; ERS: endoplasmic reticulum stress; WGCNA: weighted gene coexpression network analysis; GENIE3: GEne Network Inference with Ensemble of trees; ARDS: acute respiratory distress}


syndrome; nsp: nonstructural protein; ORFs: open reading frames; RNA seq: RNA sequencing; S: spike; E: envelope; $\mathrm{N}$ : nucleocapsid; $\mathrm{M}$ : membrane; IAV: influenza A virus; RSV: respiratory syncytial virus; ER: endoplasmic reticulum; DEGs: differentially expressed genes; DEPs: differentially expressed proteins; NDEGs: non-differentially expressed genes; NDEPs: nondifferentially expressed proteins; GO: Gene Ontology; GEPIA2: Gene Expression Profiling Interactive Analysis; HPA: the Human Protein Atlas; UPR: unfolded protein response; ROS: reactive oxygen species; TOM: topological overlap matrix; WebGestalt: WEB-based gene set analysis toolkit; PP: PredictProtein.

\section{AUTHOR CONTRIBUTIONS}

Y.J. and Q.H., conceived and designed the study. Q.H. and J.W. performed the bioinformatic analysis. H.L., L.L. and X.L. acquired open access data and performed statistical analysis. Y.J., Q.H., Y.D. and A.L. prepared the manuscript.

\section{CONFLICTS OF INTEREST}

All the authors declare that they have no competing interests.

\section{FUNDING}

This research was supported by grants from the NSFCGuangdong Joint Foundation of China (U1601225), the National Natural Science Foundation of China (81971895), and Special Support Plan for Outstanding Talents of Guangdong Province (2019JC05Y340).

\section{REFERENCES}

1. World Health Organization. Coronavirus Disease 2019 (COVID-19) Situation Report (World Health Organization, 2020).

2. Dong $\mathrm{E}, \mathrm{Du} \mathrm{H}, \mathrm{Gardner} \mathrm{L}$. An interactive web-based dashboard to track COVID-19 in real time. Lancet Infect Dis. 2020; 20:533-534.

https://doi.org/10.1016/s1473-3099(20)30120-1 PMID:32087114

3. Zhou $P$, Yang $X L$, Wang $X G$, Hu B, Zhang L, Zhang $W, S i$ $H R$, Zhu Y, Li B, Huang CL, Chen HD, Chen J, Luo Y, et al. A pneumonia outbreak associated with a new coronavirus of probable bat origin. Nature. 2020; 579:270-273.

https://doi.org/10.1038/s41586-020-2012-7 PMID: 32015507

4. Alsaadi EAJ, Jones IM. Membrane binding proteins of coronaviruses. Future Virol. 2019; 14:275-286. https://doi.org/10.2217/fvl-2018-0144

PMID:32201500

5. Muller MA, van der Hoek $L$, Voss $D$, Bader $O$, Lehmann D, Schulz AR, Kallies S, Suliman T, Fielding BC, Drosten C, Niedrig M. Human coronavirus NL63 open reading frame 3 encodes a virion-incorporated $\mathrm{N}$-glycosylated membrane protein. Virol J. 2010; 7:6. https://doi.org/10.1186/1743-422x-7-6 PMID:20078868

6. Li W, Sui J, Huang IC, Kuhn JH, Radoshitzky SR, Marasco WA, Choe H, Farzan M. The S proteins of human coronavirus NL63 and severe acute respiratory syndrome coronavirus bind overlapping regions of ACE2. Virology. 2007; 367:367-74. https://doi.org/10.1016/i.virol.2007.04.035 PMID: 17631932

7. Wu A, Peng $Y$, Huang $B$, Ding $X$, Wang $X$, Niu $P$, Meng J, Zhu Z, Zhang Z, Wang J, Sheng J, Quan L, Xia Z, et al. Genome composition and divergence of the novel coronavirus (2019-nCoV) originating in China. Cell Host Microbe. 2020; 27:325-328.

https://doi.org/10.1016/i.chom.2020.02.001 PMID: $\underline{32035028}$

8. Shang J, Ye G, Shi K, Wan Y, Luo C, Aihara H, Geng Q, Auerbach A, Li F. Structural basis of receptor recognition by SARS-CoV-2. Nature. 2020; 581:221224.

https://doi.org/10.1038/s41586-020-2179-y PMID: 32225175

9. Xu X, Chen P, Wang J, Feng J, Zhou H, Li X, Zhong W, Hao P. Evolution of the novel coronavirus from the ongoing Wuhan outbreak and modeling of its spike protein for risk of human transmission. Sci China Life Sci. 2020; 63:457-460.

https://doi.org/10.1007/s11427-020-1637-5 PMID: $\underline{32009228}$

10. Bojkova D, Klann K, Koch B, Widera M, Krause D, Ciesek S, Cinatl J, Munch C. Proteomics of SARS-CoV2 -infected host cells reveals therapy targets. Nature. 2020; 583:469-472. https://doi.org/10.1038/s41586-020-2332-7 PMID: 32408336

11. Emanuel W, Kirstin M, Vedran F, Asija D, Theresa GL, Roberto A, Filippos K, David K, Salah A, Christopher B, Anja R, Ivano L, Andranik I, et al. Bulk and single-cell gene expression profiling of SARS-CoV-2 infected human cell lines identifies molecular targets for therapeutic intervention. bioRxiv. 2020. https://doi.org/10.1101/2020.05.05.079194

12. Blanco-Melo D, Nilsson-Payant BE, Liu WC, Uhl S, Hoagland D, Moller R, Jordan TX, Oishi K, Panis M, Sachs D, Wang TT, Schwartz RE, Lim JK, et al. 
Imbalanced host response to SARS-CoV-2 drives development of COVID-19. Cell. 2020; 181:10361045.e9.

https://doi.org/10.1016/i.cell.2020.04.026

PMID: $\underline{32416070}$

13. Stukalov A, Girault V, Grass V, Bergant V, Karayel O, Urban C, Haas DA, Huang Y, Oubraham L, Wang A, Hamad SM, Piras A, Tanzer M, et al. Multi-level proteomics reveals host-perturbation strategies of SARS-CoV-2 and SARS-CoV. bioRxiv. 2020. https://doi.org/10.1101/2020.06.17.156455

14. Coombs KM, Simon PF, McLeish NJ, Zahedi-Amiri A, Kobasa D. Aptamer profiling of A549 cells infected with low-pathogenicity and high-pathogenicity influenza viruses. Viruses. 2019; 11:1028.

https://doi.org/10.3390/v11111028

PMID: 31694171

15. Sande CJ, Njunge JM, Ngoi JM, Mutunga MN, Chege T, Gicheru ET, Gardiner EM, Gwela A, Green CA, Drysdale SB, Berkley JA, Nokes DJ, Pollard AJ. Airway response to respiratory syncytial virus has incidental antibacterial effects. Nat Commun. 2019; 10:2218.

https://doi.org/10.1038/s41467-019-10222-z PMID: $\underline{31101811}$

16. Kolde R. pheatmap: Pretty Heatmaps. 2019. https://CRAN.R-project.org/package=pheatmap

17. Appelberg S, Gupta S, Akusjarvi SS, Ambikan AT, Mikaeloff F, Saccon E, Vegvari A, Benfeitas R, Sperk $M$, Stahlberg $M$, Krishnan $S$, Singh $K$, Penninger JM, et al. Dysregulation in Akt/mTOR/HIF-1 signaling identified by proteo-transcriptomics of SARS-CoV-2 infected cells. Emerg Microbes Infect. 2020; 9:17481760.

https://doi.org/10.1080/22221751.2020.1799723

PMID: $\underline{32691695}$

18. Daniloski Z, Jordan TX, Wessels HH, Hoagland DA, Kasela S, Legut M, Maniatis S, Mimitou EP, Lu L, Geller $\mathrm{E}$, Danziger $\mathrm{O}$, Rosenberg BR, Phatnani $\mathrm{H}$, et al. Identification of required host factors for SARS-CoV-2 infection in human cells. Cell. 2021; 184:92-105.e16. https://doi.org/10.1016/j.cell.2020.10.030 PMID: 33147445

19. Hemmat $N$, Derakhshani A, Baghi HB, Silvestris $N$, Baradaran B, De Summa S. Neutrophils, crucial, or harmful immune cells involved in coronavirus infection: a bioinformatics study. Front Genet. 2020; 11:641. https://doi.org/10.3389/fgene.2020.00641 PMID: $\underline{32582303}$

20. Chen $\mathrm{H}$, Zhao W, Zhang $Y$, Guo $Y$, Luo W, Wang $X$, Nie $Y$, Ye M, Huang C, Wang D, Chen M, He X, Zhao Q. Systematic analysis on multiple gene expression omnibus data sets reveals fierce immune response in hepatitis B virus-related acute liver failure. J Cell Mol Med. 2020; 24:9798-9809.

https://doi.org/10.1111/jcmm.15561

PMID: $\underline{32686296}$

21. Krajewska $M, X u L, X u$ W, Krajewski S, Kress $C L$, Cui J, Yang L, Irie F, Yamaguchi Y, Lipton SA, Reed JC. Endoplasmic reticulum protein $\mathrm{Bl}-1$ modulates unfolded protein response signaling and protects against stroke and traumatic brain injury. Brain Res. 2011; 1370:227-37. https://doi.org/10.1016/i.brainres.2010.11.015 PMID: 21075086

22. Xu Q, Reed JC. Bax inhibitor-1, a mammalian apoptosis suppressor identified by functional screening in yeast. Mol Cell. 1998; 1:337-46. https://doi.org/10.1016/s1097-2765(00)80034-9 PMID: 9660918

23. Edlich F, Banerjee $S$, Suzuki M, Cleland MM, Arnoult D, Wang C, Neutzner A, Tjandra N, Youle RJ. Bcl-x(L) retrotranslocates Bax from the mitochondria into the cytosol. Cell. 2011; 145:104-16.

https://doi.org/10.1016/i.cell.2011.02.034 PMID: 21458670

24. Yount B, Roberts RS, Sims AC, Deming D, Frieman MB, Sparks J, Denison MR, Davis N, Baric RS. Severe acute respiratory syndrome coronavirus group-specific open reading frames encode nonessential functions for replication in cell cultures and mice. J Virol. 2005; 79:14909-22.

https://doi.org/10.1128/jvi.79.23.14909-14922.2005 PMID: 16282490

25. Padhan K, Minakshi R, Towheed MAB, Jameel S. Severe acute respiratory syndrome coronavirus $3 a$ protein activates the mitochondrial death pathway through p38 MAP kinase activation. J Gen Virol. 2008; 89:1960-1969.

https://doi.org/10.1099/vir.0.83665-0

PMID: 18632968

26. Freundt EC, Yu L, Goldsmith CS, Welsh $S$, Cheng $A$, Yount B, Liu W, Frieman MB, Buchholz UJ, Screaton GR, Lippincott-Schwartz J, Zaki SR, Xu XN, et al. The open reading frame $3 a$ protein of severe acute respiratory syndrome-associated coronavirus promotes membrane rearrangement and cell death. J Virol. 2010; 84:1097-109.

https://doi.org/10.1128/jvi.01662-09

PMID: 19889773

27. Angelini MM, Neuman BW, Buchmeier MJ. Untangling membrane rearrangement in the nidovirales. DNA Cell Biol. 2014; 33:122-127.

https://doi.org/10.1089/dna.2013.2304

PMID: 24410069 
28. Cornillez-Ty CT, Liao L, Yates JR 3rd, Kuhn P, Buchmeier MJ. Severe acute respiratory syndrome coronavirus nonstructural protein 2 interacts with a host protein complex involved in mitochondrial biogenesis and intracellular signaling. J Virol. 2009; 83:10314-8.

https://doi.org/10.1128/jvi.00842-09

PMID: 19640993

29. Cottam EM, Whelband MC, Wileman T. Coronavirus NSP6 restricts autophagosome expansion. Autophagy. 2014; 10:1426-41.

https://doi.org/10.4161/auto.29309

PMID: 24991833

30. Shen B, Yi X, Sun Y, Bi X, Du J, Zhang C, Quan S, Zhang F, Sun R, Qian L, Ge W, Liu W, Liang S, et al. Proteomic and metabolomic characterization of COVID-19 patient sera. Cell. 2020; 182:59-72.e15. https://doi.org/10.1016/i.cell.2020.05.032 PMID: 32492406

31. Thoms $M$, Buschauer $R$, Ameismeier $M$, Koepke $L$, Denk $T$, Hirschenberger $M$, Kratzat $H$, Hayn $M$, Mackens-Kiani T, Cheng J, Straub JH, Sturzel CM, Frohlich $\mathrm{T}$, et al. Structural basis for translational shutdown and immune evasion by the Nsp1 protein of SARS-CoV-2. Science. 2020; 369:12491255.

https://doi.org/10.1126/science.abc8665 PMID: 32680882

32. Alonso AM, Diambra L. SARS-CoV-2 codon usage bias downregulates host expressed genes with similar codon usage. Front Cell Dev Biol. 2020; 8:831. https://doi.org/10.3389/fcell.2020.00831 PMID: 32974353

33. Kim HR, Lee GH, Ha KC, Ahn T, Moon JY, Lee BJ, Cho SG, Kim S, Seo YR, Shin YJ, Chae SW, Reed JC, Chae HJ. Bax Inhibitor-1 Is a $\mathrm{pH}$-dependent regulator of $\mathrm{Ca}^{+}$ channel activity in the endoplasmic reticulum. J Biol Chem. 2008; 283:15946-55.

https://doi.org/10.1074/ibc.m800075200

PMID: 18378668

34. Li B, Yadav RK, Jeong GS, Kim HR, Chae HJ. The characteristics of Bax inhibitor-1 and its related diseases. Curr Mol Med. 2014; 14:603-15. https://doi.org/10.2174/1566524014666140603101113 PMID: 24894176

35. Kim JH, Lee ER, Jeon K, Choi HY, Lim H, Kim SJ, Chae HJ, Park SH, Kim S, Seo YR, Kim JH, Cho SG. Role of BI-1 (TEGT)-mediated ERK1/2 activation in mitochondriamediated apoptosis and splenomegaly in BI-1 transgenic mice. Biochim Biophys Acta. 2012; 1823:876-88.

https://doi.org/10.1016/j.bbamcr.2012.01.016
PMID: 22309999

36. Henke N, Lisak DA, Schneider L, Habicht J, Pergande $M$, Methner $A$. The ancient cell death suppressor BAX inhibitor-1. Cell Calcium. 2011; 50:251-260. https://doi.org/10.1016/i.ceca.2011.05.005 PMID: 21663964

37. Robinson KS, Clements A, Williams AC, Berger CN, Frankel G. Bax inhibitor 1 in apoptosis and disease. Oncogene. 2011; 30:2391-400. https://doi.org/10.1038/onc.2010.636 PMID: 21297665

38. Hossain MK, Saha SK, Dayem AA, Kim JH, Kim K, Yang GM, Choi HY, Cho SG. Bax inhibitor-1 acts as an antiInfluenza factor by inhibiting ROS mediated cell death and augmenting heme-oxygenase 1 expression in influenza virus infected cells. Int J Mol Sci. 2018; 19:712.

https://doi.org/10.3390/ijms19030712 PMID: 29498634

39. Lai AL, Millet JK, Daniel S, Freed JH, Whittaker GR. The SARS-CoV fusion peptide forms an extended bipartite fusion platform that perturbs membrane order in a calcium-dependent manner. J Mol Biol. 2017; 429:3875-3892.

https://doi.org/10.1016/j.jmb.2017.10.017 PMID: 29056462

40. Straus MR, Bidon M, Tang T, Whittaker GR, Daniel S. FDA approved calcium channel blockers inhibit SARSCoV-2 infectivity in epithelial lung cells. bioRxiv. 2020. https://doi.org/10.1101/2020.07.21.214577

41. Wu J, Li J, Zhu G, Zhang Y, Bi Z, Yu Y, Huang B, Fu S, Tan Y, Sun J, Li X. Clinical features of maintenance hemodialysis patients with 2019 novel coronavirusinfected pneumonia in wuhan, China. Clin J Am Soc Nephrol. 2020; 15:1139-1145.

https://doi.org/10.2215/cjn.04160320

PMID: 32444393

42. Zubair AS, McAlpine LS, Gardin T, Farhadian S, Kuruvilla DE, Spudich S. Neuropathogenesis and neurologic manifestations of the coronaviruses in the age of coronavirus disease 2019: a review. JAMA Neurol. 2020; 77:1018-1027.

https://doi.org/10.1001/jamaneurol.2020.2065

PMID: 32469387

43. Lindner $D$, Fitzek $A$, Brauninger $H$, Aleshcheva $G$, Edler C, Meissner K, Scherschel K, Kirchhof P, Escher F, Schultheiss HP, Blankenberg $S$, Puschel K, Westermann D. Association of cardiac infection with SARS-CoV-2 in confirmed COVID-19 autopsy cases. JAMA Cardiol. 2020; 5:1281-1285. https://doi.org/10.1001/jamacardio.2020.3551 PMID: 32730555 
44. Link A, Hold G. First case of covid-19 in the United States. N Engl J Med. 2020; 382:e53. https://doi.org/10.1056/nejmc2004794 PMID: $\underline{32320563}$

45. Gabarre P, Dumas G, Dupont T, Darmon M, Azoulay E, Zafrani L. Acute kidney injury in critically ill patients with COVID-19. Intensive Care Med. 2020; 46:13391348.

https://doi.org/10.1007/s00134-020-06153-9

PMID: 32533197

46. Liang W, Guan W, Chen R, Wang W, Li J, Xu K, Li C, Ai $\mathrm{Q}$, Lu W, Liang $\mathrm{H}$, Li S, He J. Cancer patients in SARSCoV-2 infection: a nationwide analysis in China. Lancet Oncol. 2020; 21:335-337. https://doi.org/10.1016/s1470-2045(20)30096-6 PMID: 32066541

47. Tang Z, Kang B, Li C, Chen T, Zhang Z. GEPIA2: an enhanced web server for large-scale expression profiling and interactive analysis. Nucleic Acids Res. 2019; 47:W556-W560.

https://doi.org/10.1093/nar/gkz430 PMID: $\underline{31114875}$

48. Ritchie ME, Phipson B, Wu D, Hu Y, Law CW, Shi W, Smyth GK. Limma powers differential expression analyses for RNA-sequencing and microarray studies. Nucleic Acids Res. 2015; 43:e47. https://doi.org/10.1093/nar/gkv007 PMID: 25605792

49. Yu G, Wang LG, Han Y, He QY. clusterProfiler: an R package for comparing biological themes among gene clusters. OMICS. 2012; 16:284-7.

https://doi.org/10.1089/omi.2011.0118 PMID: 22455463

50. Morgan M, Falcon S, Gentleman R. GSEABase: Gene set enrichment data structures and methods. 2019.

51. Langfelder P, Horvath S. WGCNA: an R package for weighted correlation network analysis. BMC Bioinformatics. 2008; 9:559.

https://doi.org/10.1186/1471-2105-9-559

PMID: 19114008

52. Doncheva NT, Morris JH, Gorodkin J, Jensen L. Cytoscape stringApp: network analysis and visualization of proteomics data. J Proteome Res. 2019; 18:623-632.

https://doi.org/10.1021/acs.jproteome.8b00702 PMID: $\underline{30450911}$

53. Bindea $G$, Mlecnik $B$, Hackl $H$, Charoentong $P$, Tosolini M, Kirilovsky A, Fridman WH, Pages F, Trajanoski Z, Galon J. ClueGO: a cytoscape plug-in to decipher functionally grouped gene ontology and pathway annotation networks. Bioinformatics. 2009; 25:1091-3. https://doi.org/10.1093/bioinformatics/btp101
PMID: 19237447

54. Liao Y, Wang J, Jaehnig EJ, Shi Z, Zhang B. WebGestalt 2019: gene set analysis toolkit with revamped UIs and APIs. Nucleic Acids Res. 2019; 47:W199-W205. https://doi.org/10.1093/nar/gkz401 PMID: 31114916

55. Yu G, Wang LG, Yan GR, He QY. DOSE: an $\mathrm{R} /$ Bioconductor package for disease ontology semantic and enrichment analysis. Bioinformatics. 2015; 31:608-9.

https://doi.org/10.1093/bioinformatics/btu684 PMID: 25677125

56. Wickham H. ggplot2: Elegant Graphics for Data Analysis. 2016.

57. Huynh-Thu VA, Irrthum A, Wehenkel L, Geurts P. Inferring regulatory networks from expression data using tree-based methods. PLoS One. 2010; 5:e12776.

https://doi.org/10.1371/journal.pone.0012776

PMID: 20927193

58. Aibar S, Gonzalez-Blas CB, Moerman T, Huynh-Thu VA, Imrichova $H$, Hulselmans $G$, Rambow $F$, Marine JC, Geurts P, Aerts J, van den Oord J, Atak ZK, Wouters J, et al. SCENIC: single-cell regulatory network inference and clustering. Nat Methods. 2017; 14:1083-1086. https://doi.org/10.1038/nmeth.4463 PMID: 28991892

59. Thul PJ, Akesson L, Wiking M, Mahdessian D, Geladaki A, Ait Blal H, Alm T, Asplund A, Bjork L, Breckels LM, Backstrom A, Danielsson F, Fagerberg L, et al. A subcellular map of the human proteome. Science. 2017; 356:eaal3321. https://doi.org/10.1126/science.aal3321 PMID: 28495876 


\section{SUPPLEMENTARY MATERIALS}

\section{Supplementary Figures}

A

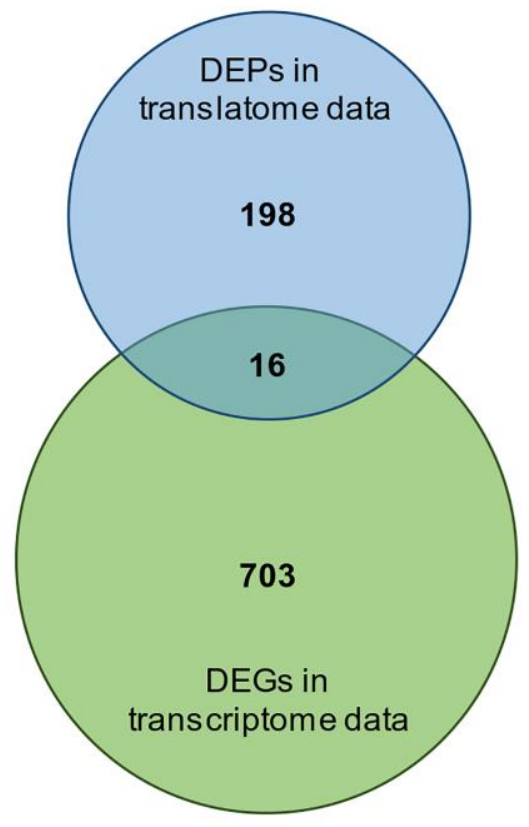

B

Trigly ceride catabolic process Neutral lipid catabolic process

Acy Igly cerol catabolic process Gly cerolipid catabolic process SMAD protein signal transduction Retinoid metabolic process Diterpenoid metabolic process Digestive sy stem process Trigly ceride metabolic process Terpenoid metabolic process Cy toplasmic v esicle part Endoplasmic reticulum lumen

Cy toplasmic v esicle lumen Vesicle lumen Collagen-containing extracellular matrix Extracellular matrix Vacuolar lumen Intermediate-density lipoprotein particle Apical cortex Chy lomicron Signaling receptor binding Structural constituent of cy toskeleton Glucokinase activ ity Hexokinase activ ity Fructokinase activ ity Mannokinase activity Interf eron receptor activ ity Lipase binding

MHC class II protein binding

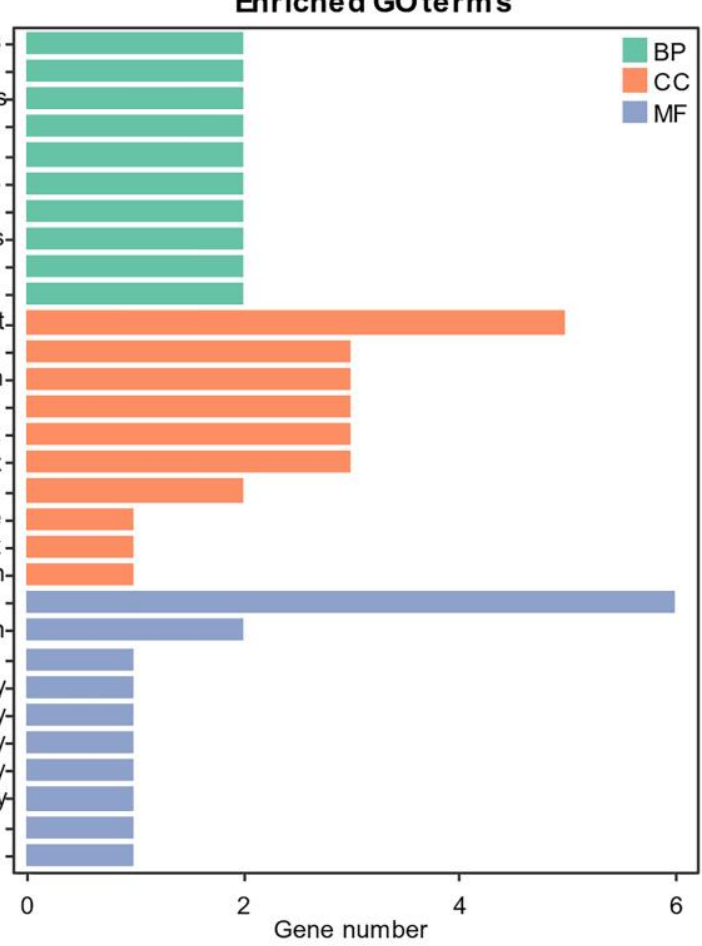

Supplementary Figure 1. GO enrichment analysis of differentially expressed proteins shared by the translatome and transcriptome. (A) Venn diagram showing the overlap of proteins encoded by the differentially expressed genes (DEGs) in the transcriptional data and differentially expressed proteins (DEPS) in the translational data. (B) GO term enrichment analysis for the 16 proteins shared by DEG-encoded proteins and DEPs with $P$ value < 0.05. (BP: Biological Process; CC: Cellular Component; MF: Molecular Function). 


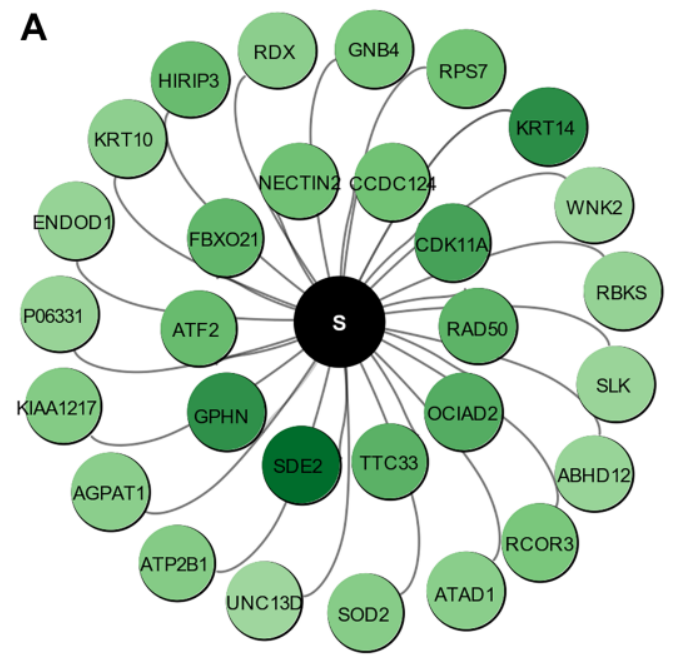

B

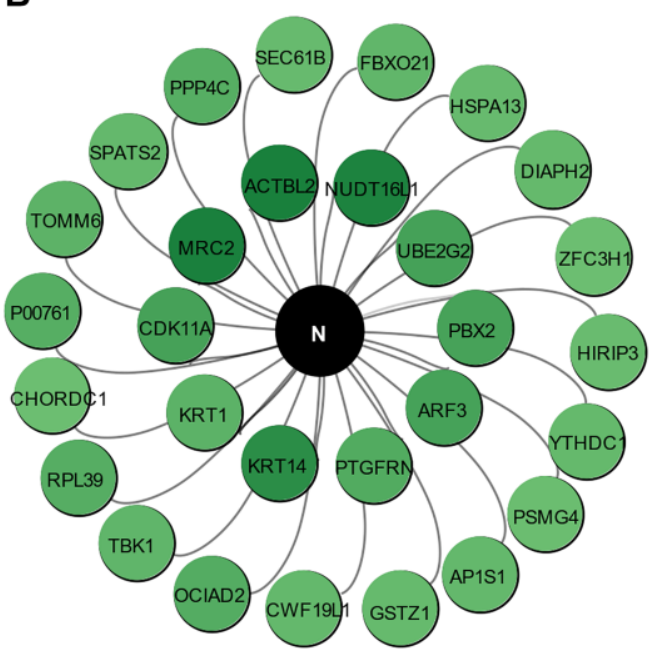

C

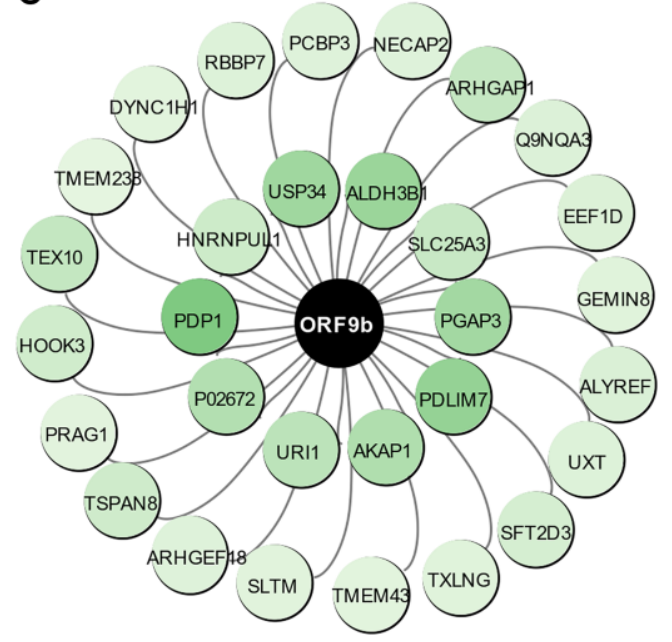

D

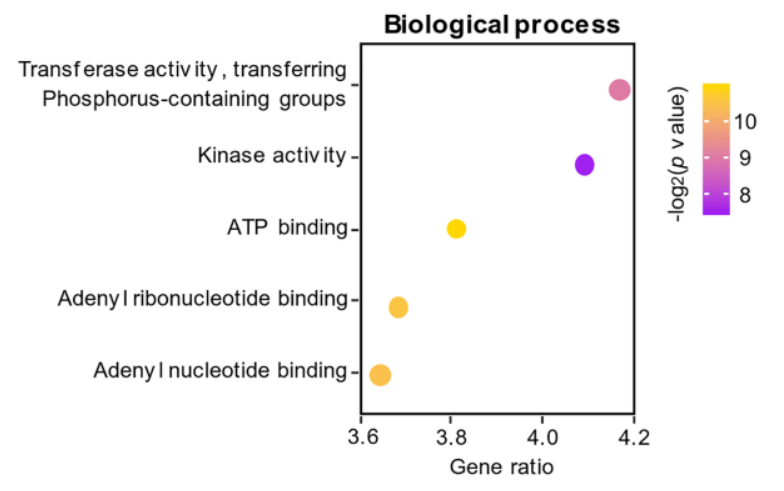

E

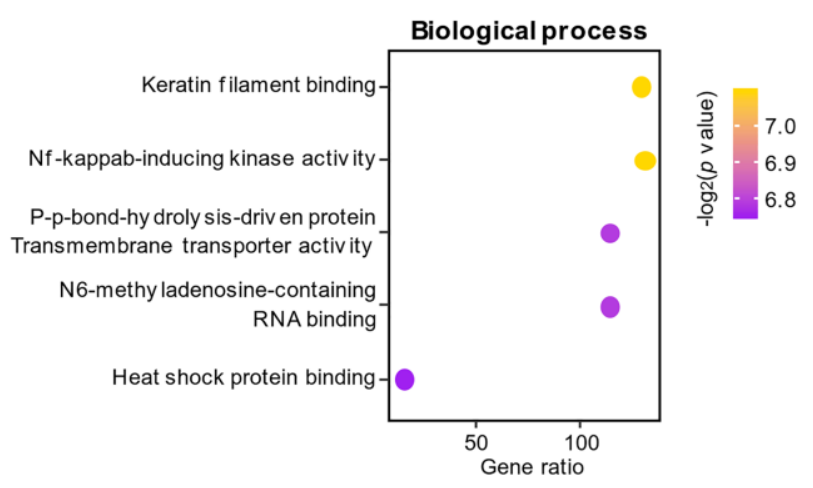

$\mathbf{F}$

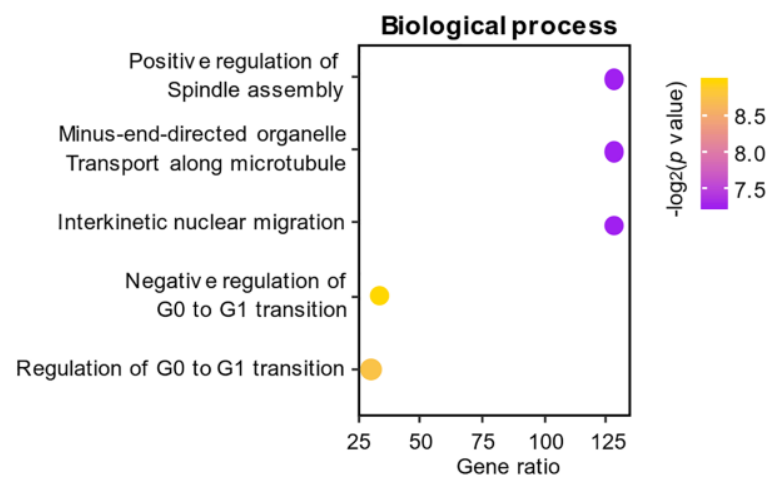

Supplementary Figure 2. Functional prediction for the other three viral proteins in the blue module. (A-C) The paired associations of the other three viral proteins, S (A), N (B) and ORF9b (C), and the top 30 high-weight host proteins for regulation predicted by GENIE3. The color depth represents the weight of the pairing between viral proteins and each host protein. (D-F) Enrichment analysis of biological processes of host proteins regulated by the viral proteins $S(D), N(E)$ and ORF9b (F). 
SARS-CoV-2: length $29903 \mathrm{nt}$

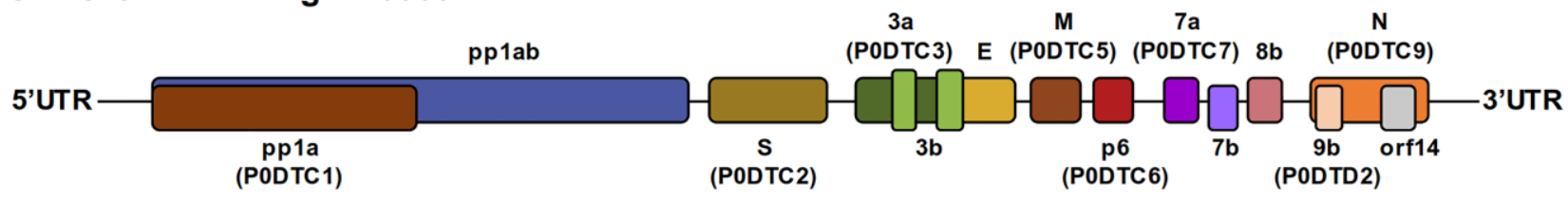

PP1A : length 4405 nt

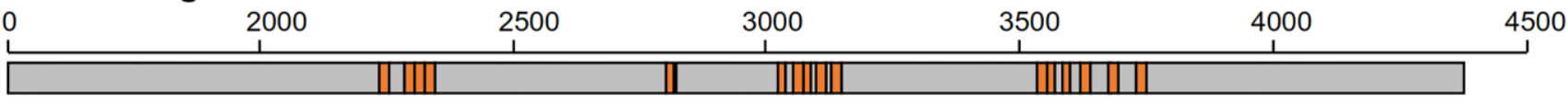

S : length $1273 \mathrm{nt}$

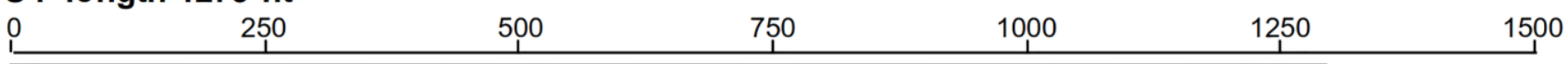

ORF3a : length 275 nt

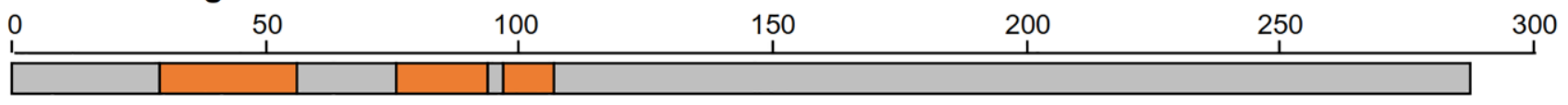

ORF6 : length $61 \mathrm{nt}$

\begin{tabular}{|c|c|c|c|c|c|}
\hline 15 & 30 & 45 & 60 & 75 & 90 \\
\hline I & & & $\square$ & & \\
\hline $\mathrm{N}$ : length $419 \mathrm{nt}$ & & & & & \\
\hline $0 \quad 70$ & 140 & 210 & 280 & 350 & 420 \\
\hline
\end{tabular}

ORF9b: length $97 \mathrm{nt}$

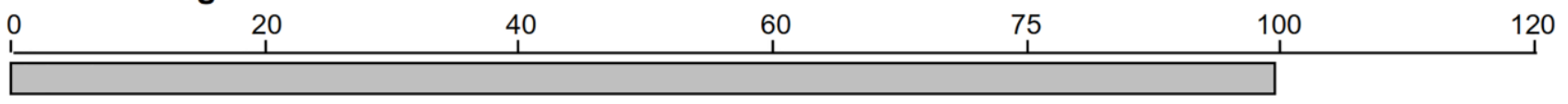

\section{TMBIM6 : length 237 nt}

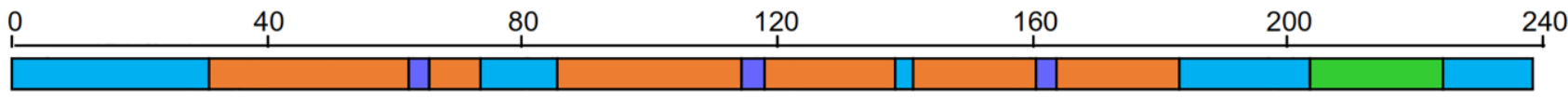

Cytoplasmic $\square$ Intramembrane $\square$ Transmembrane $\square$ Extracellular $\square$ Lumenal

Supplementary Figure 3. Sketch of the functional domains of TMBIM6 and the six viral proteins. The genome composition of SARS-CoV-2 and a schematic diagram of the protein domains of TMBIM6 and the six viral proteins. Specific domains are shown in distinct colors. Information on the domains of TMBIM6, PP1A, S and ORF3a was collected from the UniProt Consortium, and the others were predicted with PredictProtein (PP). 

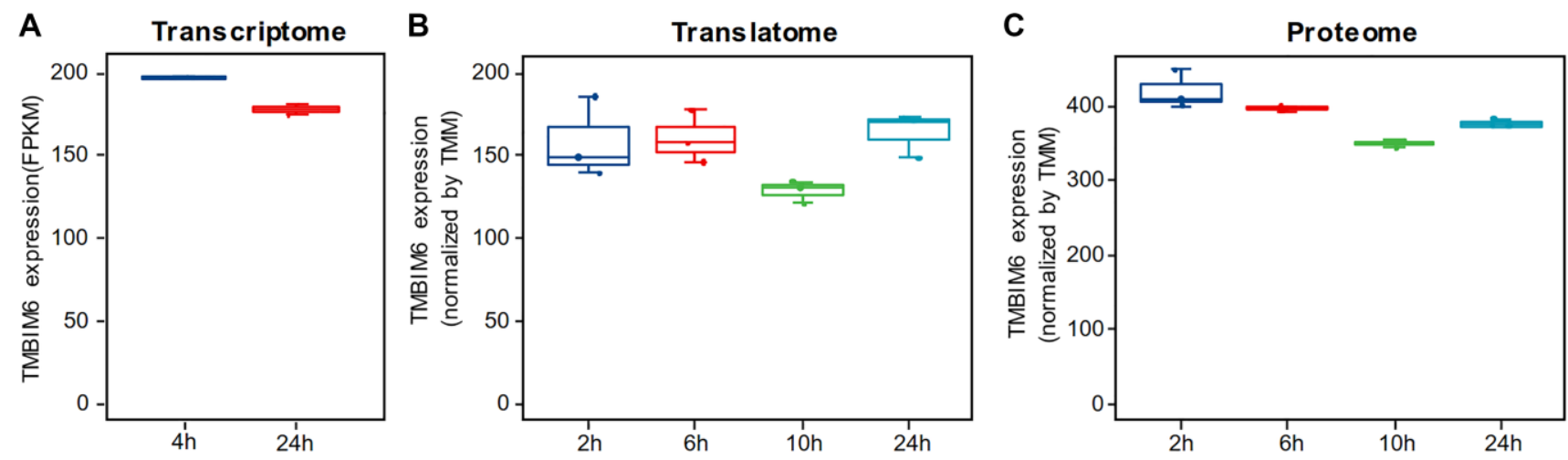

Supplementary Figure 4. Expression of TMBIM6 in the control group. The expression of TMBIM6 at different times in mock-infected cells from multiomics data. (A) The gene expression of TMBIM6 in the transcriptome in normal cells. ( $P$ value $>0.05$, comparison to $4 \mathrm{~h}$, $n=2$ ). The $P$ value was calculated with Limma-voom R package following the method reported by Ritchie ME et al. [48]. (B) Nascent peptide synthesis of TMBIM6 in the translatome of mock-infected cells. $(n=3, P$ value $>0.05$, comparison to 2 h) (C) The protein expression of TMBIM6 in the proteome of mock-infected cells. ( $n=3, P$ value $>0.05$, comparison to $2 \mathrm{~h}$ ). 
A

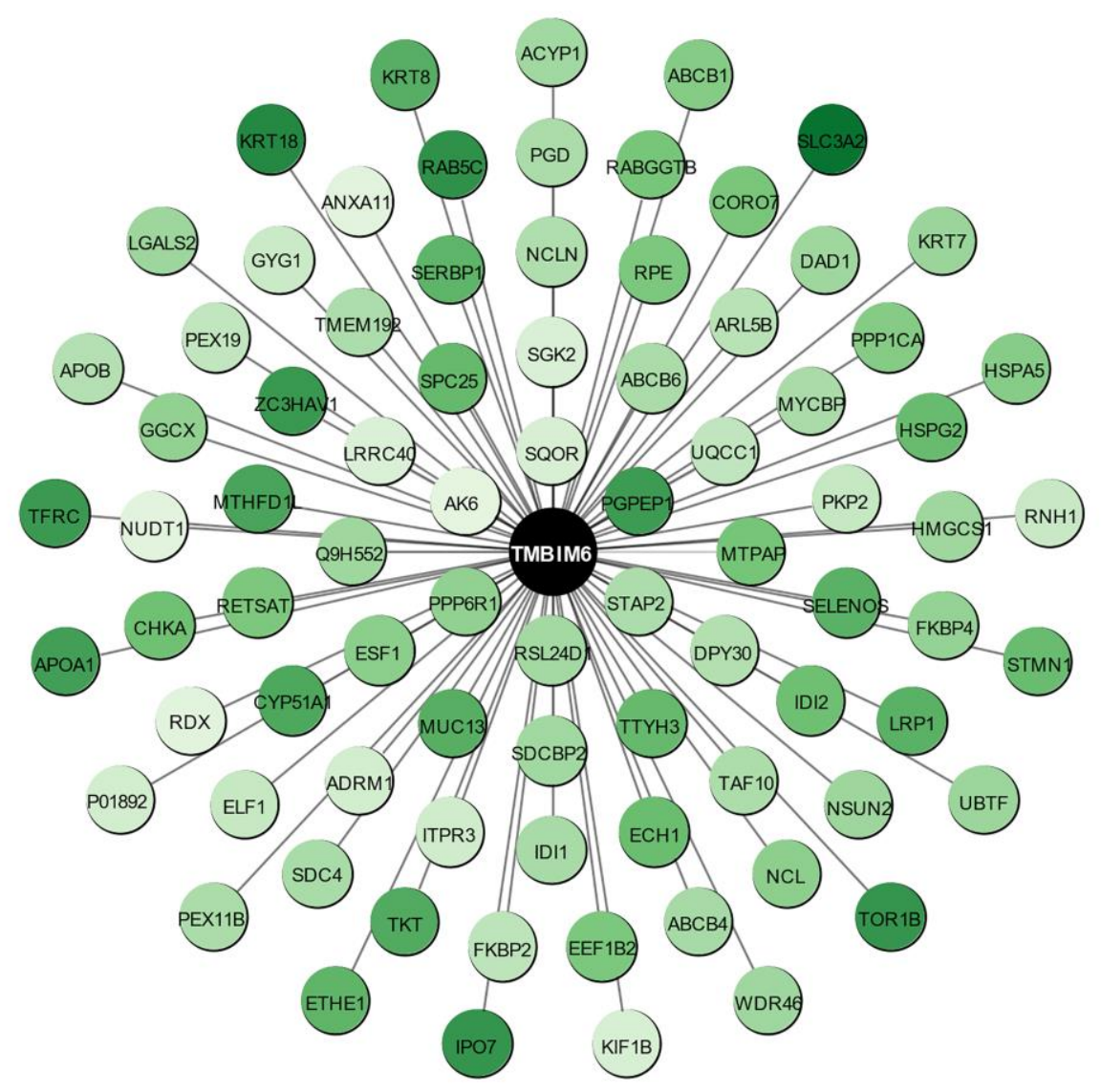

B
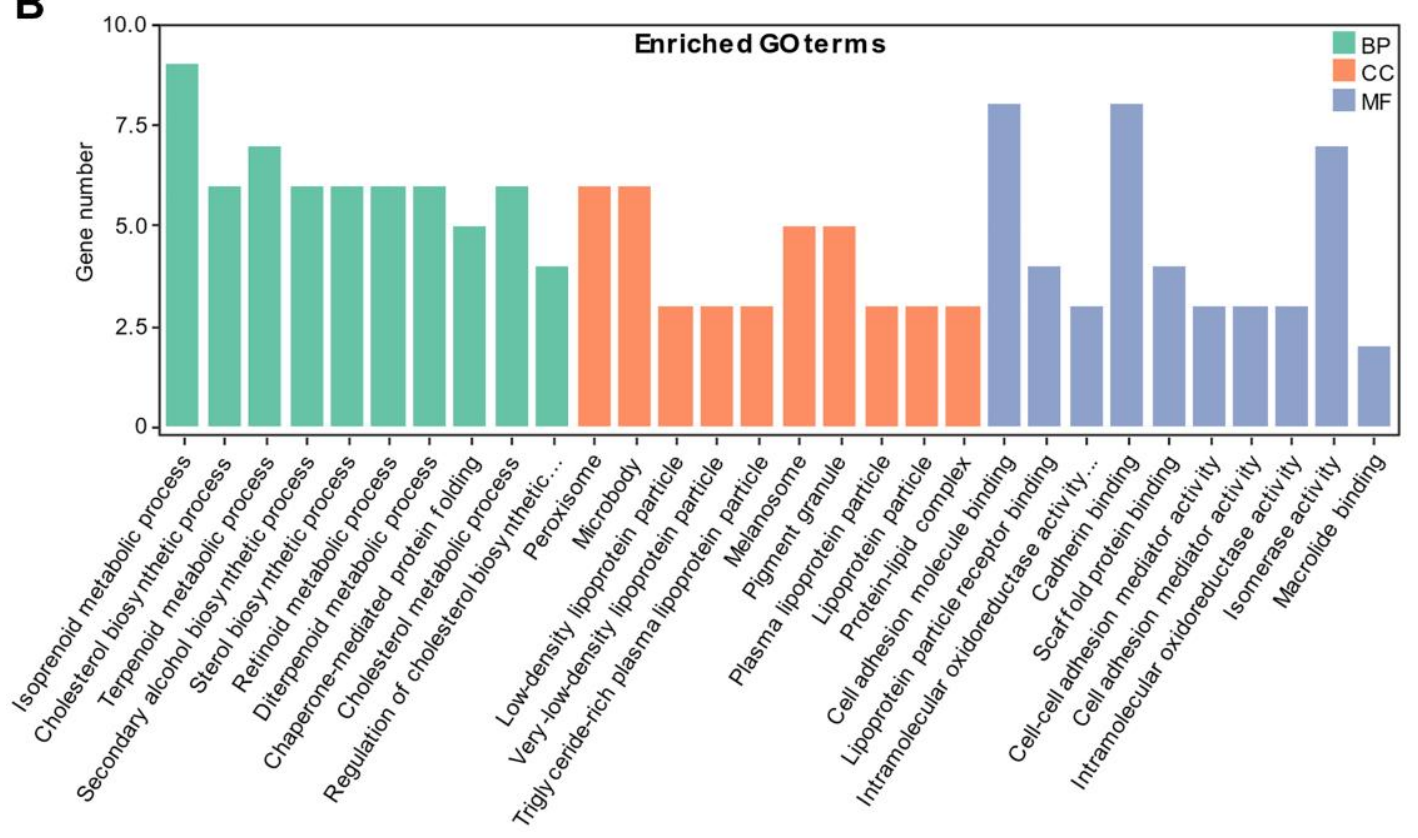

Supplementary Figure 5. Enrichment analysis of the proteins coexpressed with TMBIM6. (A) Association of TMBIM6 with the coexpressed proteins in the blue module. The color depth represents the weight of the pairing between TMBIM6 and each host protein. (B) GO term enrichment analysis of the proteins coexpressed with TMBIM6 ( $P$ value $<0.05)$. (BP: Biological Process; CC: Cellular Component; MF: Molecular Function). 


\section{Supplementary Tables}

Supplementary Table 1. A549 proteins dysregulated by infection by indicated influenza strains.

\begin{tabular}{|c|c|c|c|c|c|}
\hline \multirow{2}{*}{ Protein } & \multicolumn{5}{|c|}{ Fold-Change Compared to Sham-Infected H1N1 Viruses } \\
\hline & PR8 & RV733 & pdm09 & H5N1 & H7N9 \\
\hline \multicolumn{6}{|c|}{ Up-Regulated Proteins } \\
\hline ISG15 & 15.9 & 1.03 & 0.96 & 1.33 & 1.1 \\
\hline OAS1 & 5.06 & 0.99 & 1.08 & 0.97 & 0.96 \\
\hline CCL5 & 3.11 & 1.06 & 1.09 & 4.18 & 1.62 \\
\hline STAT1 & 3.09 & 1.26 & 0.85 & 1.02 & 1 \\
\hline B2M & 2.72 & 0.97 & 1.11 & 1.12 & 0.99 \\
\hline APOL1 & 2.68 & 0.98 & 0.99 & 0.99 & 0.92 \\
\hline $\mathrm{CD} 274$ & 2.09 & 1.06 & 1.05 & 1.27 & 1.13 \\
\hline CTSS & 2 & 0.99 & 1.05 & 0.79 & 0.59 \\
\hline SERPINE1 & 1.99 & 1 & 1.1 & 0.89 & 0.7 \\
\hline IFNL1 & 1.97 & 1 & 0.99 & 1.52 & 1.21 \\
\hline F2 & 1.84 & 1.03 & 1 & 0.97 & 0.89 \\
\hline PLAUR & 1.8 & 0.98 & 1.05 & 1.05 & 0.85 \\
\hline MDK & 1.8 & 1.01 & 0.97 & 1.02 & 0.93 \\
\hline $\mathrm{CFB}$ & 1.75 & 1.04 & 1.03 & 1.03 & 0.96 \\
\hline THPO & 1.01 & 1.58 & 1.01 & 1 & 1.1 \\
\hline L1CAM & 1.21 & 1.28 & 1.83 & 1.57 & 1.47 \\
\hline CXCL8 & 1.26 & 1 & 0.99 & 2.26 & 2.3 \\
\hline CD207 & 1.1 & 1.05 & 1.06 & 1.61 & 1.38 \\
\hline F9 & 2.21 & 1.03 & 1.14 & 1.53 & 1.29 \\
\hline \multicolumn{6}{|c|}{ Down-regulated proteins } \\
\hline PPID & 0.66 & 1.15 & 0.95 & 0.97 & 1.03 \\
\hline TGM3 & 0.88 & 0.61 & 1.21 & 0.75 & 0.9 \\
\hline PGAM1 & 1.05 & 0.83 & 0.39 & 0.54 & 0.5 \\
\hline MDH1 & 1.01 & 1.02 & 0.48 & 0.59 & 0.83 \\
\hline LDHB & 0.97 & 1.19 & 0.61 & 0.84 & 1.02 \\
\hline ENO1 & 0.91 & 0.96 & 0.63 & 0.77 & 0.82 \\
\hline PCSK9 & 0.8 & 0.92 & 1.07 & 0.17 & 0.11 \\
\hline DKK1 & 0.85 & 0.87 & 0.92 & 0.19 & 0.17 \\
\hline DKK4 & 0.88 & 0.91 & 0.97 & 0.25 & 0.22 \\
\hline APP & 0.93 & 0.94 & 0.99 & 0.27 & 0.12 \\
\hline SPINT2 & 0.93 & 0.87 & 0.95 & 0.37 & 0.19 \\
\hline TNFRSF4 & 1.01 & 0.53 & 0.56 & 0.39 & 0.54 \\
\hline IGFBP4 & 1.28 & 0.95 & 1.06 & 0.41 & 0.21 \\
\hline PGD & 0.98 & 1.12 & 0.8 & 0.44 & 0.66 \\
\hline FN1 & 1.12 & 0.94 & 0.95 & 0.47 & 0.4 \\
\hline TGFBI & 0.87 & 0.95 & 0.95 & 0.48 & 0.39 \\
\hline SGTA & 0.93 & 1.01 & 0.65 & 0.49 & 0.8 \\
\hline GAPDH & 0.97 & 1 & 0.7 & 0.5 & 0.83 \\
\hline FSTL3 & 1.49 & 0.92 & 1.04 & 0.5 & 0.33 \\
\hline FN1 & 1.12 & 0.95 & 0.94 & 0.53 & 0.47 \\
\hline
\end{tabular}




\begin{tabular}{|c|c|c|c|c|c|}
\hline CTSA & 0.75 & 0.94 & 1.04 & 0.53 & 0.35 \\
\hline MICB & 0.88 & 0.93 & 1 & 0.57 & 0.6 \\
\hline NOTCH3 & 1.06 & 0.9 & 0.95 & 0.59 & 0.47 \\
\hline PKM2 & 0.8 & 1.1 & 1.38 & 0.59 & 0.81 \\
\hline LRIG3 & 1.5 & 0.87 & 0.92 & 0.59 & 0.63 \\
\hline MFGE8 & 0.91 & 0.94 & 1.05 & 0.63 & 0.43 \\
\hline PEX5 & 0.98 & 0.71 & 0.73 & 0.63 & 0.75 \\
\hline WNK3 & 1.1 & 0.93 & 0.86 & 0.63 & 0.77 \\
\hline TNFRSF 21 & 0.96 & 0.92 & 0.96 & 0.63 & 0.43 \\
\hline SFRP1 & 1.27 & 1 & 0.98 & 0.64 & 0.45 \\
\hline TNFRSF1A & 0.74 & 0.97 & 1.09 & 0.64 & 0.46 \\
\hline FSTL1 & 1.28 & 0.92 & 1.02 & 0.65 & 0.44 \\
\hline IGFBP7 & 1.06 & 0.96 & 1 & 0.65 & 0.53 \\
\hline NRP1 & 1.09 & 0.94 & 0.89 & 0.65 & 0.53 \\
\hline CSF3R & 1.03 & 0.75 & 0.83 & 0.66 & 0.75 \\
\hline C3 & 1.12 & 0.96 & 1 & 0.66 & 0.61 \\
\hline $\mathrm{CFH}$ & 1.54 & 1 & 0.96 & 0.66 & 0.52 \\
\hline STC1 & 1.19 & 0.89 & 1.05 & 0.69 & 0.37 \\
\hline FGFR1 & 1.02 & 0.94 & 1.02 & 0.69 & 0.47 \\
\hline CTSV & 0.83 & 0.98 & 1.08 & 0.74 & 0.52 \\
\hline CST3 & 1.39 & 0.94 & 1.1 & 0.86 & 0.55 \\
\hline PLXNB2 & 1.05 & 1.02 & 1.14 & 0.71 & 0.58 \\
\hline LGALS8 & 1.18 & 0.92 & 0.92 & 0.78 & 0.59 \\
\hline NRG1 & 1.21 & 1.03 & 1.24 & 0.94 & 0.6 \\
\hline GNS & 0.95 & 1.04 & 1.09 & 0.75 & 0.6 \\
\hline MICA & 0.85 & 1.04 & 1.18 & 0.68 & 0.61 \\
\hline \multicolumn{6}{|l|}{ LAMA1 } \\
\hline LAMB1 & 0.76 & 1.09 & 1.14 & 0.79 & 0.62 \\
\hline \multicolumn{6}{|l|}{ LAMC1 } \\
\hline THBS1 & 1.05 & 1.01 & 1.04 & 0.68 & 0.62 \\
\hline TIMP2 & 0.97 & 0.93 & 1.03 & 0.85 & 0.62 \\
\hline MMP7 & 0.93 & 0.99 & 1.03 & 0.93 & 0.63 \\
\hline LCN2 & 0.78 & 0.96 & 1.03 & 0.87 & 0.63 \\
\hline GRN & 1.04 & 0.96 & 1.04 & 0.67 & 0.63 \\
\hline TFPI & 0.8 & 1.03 & 1.03 & 1.1 & 0.63 \\
\hline GFRA1 & 0.77 & 0.97 & 0.99 & 0.75 & 0.63 \\
\hline MET & 1.23 & 1.03 & 1.11 & 0.89 & 0.64 \\
\hline KIR2DL4 & 0.92 & 1.01 & 0.92 & 0.77 & 0.65 \\
\hline LGALS3BP & 1.49 & 0.97 & 1.01 & 0.83 & 0.65 \\
\hline
\end{tabular}

Values represent protein fold-changes compared to mock-infected. Proteins sorted first by upregulation and from left-most virus column to right-most; then sorted by downregulation from left to right. 
Supplementary Table 2. Differentially airway expressed proteins compared between children with and without RSV infection.

\begin{tabular}{|c|c|c|c|c|}
\hline Protein & $\begin{array}{l}\log _{10} \text { mean expression in } \\
\text { RSV-negative group }\end{array}$ & $\begin{array}{l}\log _{10} \text { mean } \\
\text { expression in RSV- } \\
\text { positive group }\end{array}$ & $P . v a l u e$ & FDR \\
\hline CAT & 5.114667484 & 5.301170781 & $1.28 \mathrm{E}-08$ & $6.15 \mathrm{E}-06$ \\
\hline HP & 4.943199091 & 5.132428762 & 2.00E-08 & 7.20E-06 \\
\hline MNDA & 5.017074398 & 5.433427343 & $4.17 \mathrm{E}-08$ & $1.15 \mathrm{E}-05$ \\
\hline RAP1B & 4.949246377 & 5.183158396 & 4.77E-08 & $1.15 \mathrm{E}-05$ \\
\hline MYH9 & 5.518510344 & 5.823424089 & 7.16E-08 & $1.48 \mathrm{E}-05$ \\
\hline MMP9 & 4.708812819 & 5.100992611 & $1.29 \mathrm{E}-07$ & $2.07 \mathrm{E}-05$ \\
\hline EMC7 & 4.490219365 & 4.717223378 & $1.71 \mathrm{E}-07$ & 2.33E-05 \\
\hline ITGAM & 5.292602525 & 5.593034483 & $1.92 \mathrm{E}-07$ & 2.33E-05 \\
\hline MGAM & 4.419582833 & 4.778247554 & $6.23 \mathrm{E}-07$ & $6.42 \mathrm{E}-05$ \\
\hline APMAP & 5.074535297 & 5.32660057 & 7.62E-07 & 7.32E-05 \\
\hline MPO & 6.140891698 & 6.318606892 & $2.25 \mathrm{E}-06$ & 0.000170608 \\
\hline BPI & 5.097592111 & 5.404436702 & $3.30 \mathrm{E}-06$ & 0.000207032 \\
\hline AZU1 & 4.886635066 & 5.161970143 & 7.38E-06 & 0.000364581 \\
\hline MYO1F & 4.511891333 & 5.01680507 & $7.58 \mathrm{E}-06$ & 0.000364581 \\
\hline SERPINA3 & 5.055420395 & 5.292196687 & $1.07 \mathrm{E}-05$ & 0.000466571 \\
\hline HSP90AB1 & 5.139026935 & 5.341131197 & $1.10 \mathrm{E}-05$ & 0.000466571 \\
\hline ANXA6 & 5.655306917 & 5.853015652 & $1.25 \mathrm{E}-05$ & 0.000491166 \\
\hline PADI4 & 4.589404054 & 4.991695909 & $1.40 \mathrm{E}-05$ & 0.000530222 \\
\hline EPX & 4.604312816 & 5.590438279 & $1.85 \mathrm{E}-05$ & 0.000679374 \\
\hline GCA & 4.863981185 & 5.270911516 & $1.93 \mathrm{E}-05$ & 0.000679374 \\
\hline MYDGF & 4.339989914 & 4.756786345 & $1.98 \mathrm{E}-05$ & 0.000679374 \\
\hline CANX & 5.048917062 & 5.2431655 & $2.10 \mathrm{E}-05$ & 0.000681136 \\
\hline SRSF3 & 4.218063025 & 4.437589361 & $2.44 \mathrm{E}-05$ & 0.000765642 \\
\hline LCN2 & 5.326103066 & 5.503063103 & $3.96 \mathrm{E}-05$ & 0.001119608 \\
\hline HP1BP3 & 4.293497481 & 4.539154806 & 4.09E-05 & 0.001134989 \\
\hline ELANE & 4.93978268 & 5.127932395 & 5.37E-05 & 0.001389106 \\
\hline RAB10 & 4.238116644 & 4.440085185 & $6.31 \mathrm{E}-05$ & 0.001459194 \\
\hline LCP1 & 5.257523438 & 5.464338395 & $6.56 \mathrm{E}-05$ & 0.001478903 \\
\hline CPNE1 & 4.726319498 & 4.926530454 & $6.84 \mathrm{E}-05$ & 0.001516836 \\
\hline SH3GLB1 & 4.297194109 & 4.602835986 & 0.000127054 & 0.002359089 \\
\hline KIF26B & 5.257184823 & 5.456586151 & 0.00015695 & 0.002760015 \\
\hline CTSS & 3.911710292 & 4.087836721 & 0.000159594 & 0.002772701 \\
\hline ACOX 1 & 4.419834462 & 4.698403156 & 0.000168715 & 0.002868469 \\
\hline PSME2 & 4.264533049 & 4.521832593 & 0.000238025 & 0.003813696 \\
\hline ITGB2 & 5.05813684 & 5.266248026 & 0.000245421 & 0.003879711 \\
\hline HNRNPAB & 4.438715726 & 4.649400188 & 0.000248558 & 0.003879711 \\
\hline GRHPR & 4.266930668 & 4.448939488 & 0.000250217 & 0.003879711 \\
\hline PRTN3 & 4.807077714 & 5.067267571 & 0.000270166 & 0.004058111 \\
\hline ALOX5 & 4.541069623 & 5.083127355 & 0.000355657 & 0.005128569 \\
\hline DCD & 4.394689684 & 4.690283061 & 0.000384398 & 0.005488132 \\
\hline NDUFA11 & 4.164125357 & 4.48487794 & 0.0005119 & 0.006963769 \\
\hline DYSF & 4.666788893 & 4.996987759 & 0.000527755 & 0.007112359 \\
\hline
\end{tabular}




\begin{tabular}{|c|c|c|c|c|}
\hline MYH14 & 4.638495555 & 4.866330565 & 0.000572568 & 0.007543538 \\
\hline S100A12 & 4.941173281 & 5.304467151 & 0.000654068 & 0.008168783 \\
\hline TMED2 & 4.271798725 & 4.485082471 & 0.000713832 & 0.00857788 \\
\hline MX1 & 4.881645757 & 5.224818513 & 0.001023358 & 0.011012558 \\
\hline NDUFA12 & 4.244562117 & 4.587710606 & 0.001158382 & 0.012058949 \\
\hline CAMP & 4.721340789 & 4.916958008 & 0.001269447 & 0.012800992 \\
\hline $\mathrm{CKB}$ & 4.023948761 & 4.257760936 & 0.001290731 & 0.012903917 \\
\hline CYBB & 4.710832198 & 4.988796789 & 0.001421212 & 0.013074125 \\
\hline PLBD1 & 4.537548032 & 4.768849146 & 0.001442147 & 0.013074125 \\
\hline ORM1 & 4.819126792 & 5.02006486 & 0.001490856 & 0.013074125 \\
\hline PPIC & 3.885470221 & 4.153959038 & 0.001495999 & 0.013074125 \\
\hline TCEB2 & 4.138376822 & 4.333947036 & 0.001651799 & 0.013880687 \\
\hline PCMT1 & 4.247477859 & 4.439112435 & 0.001955052 & 0.015575607 \\
\hline TLN1 & 4.679858981 & 4.872637538 & 0.002140904 & 0.016788022 \\
\hline TRAP1 & 4.294250303 & 4.574332382 & 0.002494947 & 0.019035414 \\
\hline ARPC5 & 4.272058349 & 4.57568884 & 0.002800627 & 0.020710274 \\
\hline SERPINB10 & 4.224020012 & 4.475496364 & 0.003130255 & 0.022456852 \\
\hline PTPRC & 4.830039126 & 5.076758062 & 0.003299715 & 0.023324454 \\
\hline RETN & 4.312720031 & 4.543402821 & 0.00348406 & 0.024153914 \\
\hline EHD1 & 4.231194433 & 4.425856813 & 0.004084851 & 0.027072375 \\
\hline FTH1 & 4.704243637 & 4.901463071 & 0.004183767 & 0.02742425 \\
\hline ANPEP & 4.201451437 & 4.441455196 & 0.004184005 & 0.02742425 \\
\hline RBM39 & 3.96989748 & 4.233939707 & 0.004779836 & 0.029967494 \\
\hline GNS & 4.23532213 & 4.587026036 & 0.005160762 & 0.031802644 \\
\hline PLA2G4B & 3.319511058 & 3.538414019 & 0.005824789 & 0.034997275 \\
\hline OLFM4 & 4.88179311 & 5.225560007 & 0.00641208 & 0.037894343 \\
\hline GSTO1 & 4.329614511 & 4.507592378 & 0.006545645 & 0.038213845 \\
\hline HPRT1 & 4.02449349 & 4.246696767 & 0.00698618 & 0.039818463 \\
\hline MAPRE1 & 4.341162146 & 4.520932463 & 0.007341398 & 0.041204574 \\
\hline TOMM40 & 4.268530324 & 4.467013054 & 0.008485019 & 0.04565447 \\
\hline CALR & 4.839972595 & 5.081679102 & 0.009534153 & 0.049993634 \\
\hline RPL10 & 5.038303341 & 4.825068869 & $1.52 \mathrm{E}-09$ & $2.20 \mathrm{E}-06$ \\
\hline CES2 & 4.739516838 & 4.539885993 & 8.27E-09 & $5.96 \mathrm{E}-06$ \\
\hline ILF3 & 4.480517964 & 4.078762258 & 8.69E-08 & $1.57 \mathrm{E}-05$ \\
\hline PSMD11 & 4.563260965 & 4.311806318 & 4.97E-07 & $5.51 \mathrm{E}-05$ \\
\hline HNRNPR & 4.818464478 & 4.486926813 & $1.11 \mathrm{E}-06$ & $9.97 \mathrm{E}-05$ \\
\hline CAMK2D & 4.64026272 & 4.323096185 & $1.43 \mathrm{E}-06$ & 0.00012137 \\
\hline DNAJB1 & 4.410924636 & 4.080041455 & $3.16 \mathrm{E}-06$ & 0.000207032 \\
\hline KRT19 & 4.390867068 & 4.073041713 & $3.90 \mathrm{E}-06$ & 0.000234244 \\
\hline RPS25 & 4.494494689 & 4.1554186 & $5.95 \mathrm{E}-06$ & 0.000317985 \\
\hline NDUFA5 & 4.252835291 & 3.800853144 & 7.36E-06 & 0.000364581 \\
\hline CORO1B & 4.311809276 & 3.840996573 & $1.26 \mathrm{E}-05$ & 0.000491166 \\
\hline BAZ1B & 4.331136327 & 4.071409626 & $2.58 \mathrm{E}-05$ & 0.000792894 \\
\hline KLK10 & 4.610027666 & 4.350204027 & $3.07 \mathrm{E}-05$ & 0.000903416 \\
\hline PRPF19 & 4.276525779 & 4.099943658 & $4.18 \mathrm{E}-05$ & 0.001137632 \\
\hline RPL17 & 4.588634204 & 4.389761832 & $5.56 \mathrm{E}-05$ & 0.001389106 \\
\hline AGR3 & 4.641451574 & 4.197310764 & $5.75 \mathrm{E}-05$ & 0.001389653 \\
\hline
\end{tabular}




\begin{tabular}{|c|c|c|c|c|}
\hline IPO9 & 4.547905831 & 4.12918725 & $6.38 \mathrm{E}-05$ & 0.001459194 \\
\hline RBMX & 4.538922051 & 4.362244876 & 0.000104859 & 0.002071318 \\
\hline CSNK2B & 4.472511277 & 4.272629227 & 0.000117422 & 0.002257634 \\
\hline RPS6 & 5.136831181 & 4.9496338855 & 0.000138693 & 0.002531581 \\
\hline PGRMC2 & 4.377971929 & 4.143431274 & 0.000149387 & 0.002692698 \\
\hline SUGP2 & 4.1219491 & 3.919151077 & 0.000176012 & 0.002951263 \\
\hline RUVBL2 & 4.641147664 & 4.39312991 & 0.000197676 & 0.003276429 \\
\hline RPL29 & 4.456132726 & 4.228694489 & 0.000388869 & 0.005497545 \\
\hline PSMA3 & 4.375285194 & 4.160471533 & 0.000575443 & 0.007543538 \\
\hline KHDRBS1 & 4.533721407 & 4.324410349 & 0.000594524 & 0.007723456 \\
\hline ARCN1 & 4.543623773 & 4.33631855 & 0.00077428 & 0.009189714 \\
\hline ABHD11 & 4.608569859 & 4.25672282 & 0.00078057 & 0.009189714 \\
\hline NDUFA2 & 4.551278157 & 4.340961981 & 0.000866266 & 0.009759027 \\
\hline RPS16 & 4.692821753 & 4.498170909 & 0.000999374 & 0.010835322 \\
\hline RPS14 & 4.473910141 & 4.197533028 & 0.001297551 & 0.012903917 \\
\hline SUMF2 & 4.3979048 & 4.144564048 & 0.001351827 & 0.013012456 \\
\hline NRAS & 4.485524833 & 4.283700719 & 0.001362608 & 0.013012456 \\
\hline $\mathrm{DCN}$ & 4.391247118 & 3.895792297 & 0.001395888 & 0.013074125 \\
\hline RPS29 & 4.434367987 & 4.230899371 & 0.001422306 & 0.013074125 \\
\hline PON2 & 4.126202606 & 3.889726328 & 0.001425059 & 0.013074125 \\
\hline DSC2 & 4.75835541 & 4.574709691 & 0.001521189 & 0.013214188 \\
\hline NAV3 & 4.160374551 & 3.975599012 & 0.001617661 & 0.013733623 \\
\hline VSNL1 & 4.528289229 & 4.285824839 & 0.001655671 & 0.013880687 \\
\hline SAP18 & 4.291686773 & 4.053549637 & 0.001802984 & 0.014772177 \\
\hline ARPC1A & 4.56710576 & 4.379795065 & 0.001872618 & 0.015256022 \\
\hline ТРPР3 & 4.844516599 & 4.626516636 & 0.001890712 & 0.015316895 \\
\hline TUBB6 & 4.331582035 & 4.111439776 & 0.002667592 & 0.019930921 \\
\hline BPIFB2 & 4.719890074 & 4.534950525 & 0.002936209 & 0.021383907 \\
\hline SPRR1B & 4.599614991 & 4.414814995 & 0.003070743 & 0.022140054 \\
\hline $\mathrm{PC}$ & 4.592197127 & 4.183016157 & 0.003386857 & 0.023593468 \\
\hline POLDIP2 & 4.568791291 & 4.218528593 & 0.003640583 & 0.024880191 \\
\hline ABHD10 & 4.227812135 & 4.040881793 & 0.004530498 & 0.028653414 \\
\hline NCF4 & 4.696260088 & 4.439957592 & 0.006964206 & 0.039818463 \\
\hline C2orf54 & 4.304826848 & 4.091812607 & 0.007882412 & 0.043632633 \\
\hline HADH & 4.723118282 & 4.528480606 & 0.007927704 & 0.043632633 \\
\hline CMAS & 4.053655261 & 3.795188414 & 0.007979096 & 0.043748506 \\
\hline AIMP2 & 4.321933547 & 4.144490597 & 0.008364574 & 0.045344796 \\
\hline DHX15 & 4.291289134 & 4.063572284 & 0.008698955 & 0.046631573 \\
\hline
\end{tabular}

